\title{
Anti-inflammatory properties of the ethanol extract from Clerodendrum cyrtophyllum Turcz based on in vitro and in vivo studies
}

\author{
Thu Hang Nguyen ${ }^{\mathrm{a}, \mathrm{b}}$, Amandine Nachtergael ${ }^{\mathrm{c}}$, Thi Mai Nguyen ${ }^{\mathrm{a}, \mathrm{d}}$, Valérie Cornet ${ }^{\mathrm{a}}$, Pierre Duez , $^{\mathrm{c}}$ \\ Marc Mullere, Duong Thi Ly Huong ${ }^{\mathrm{f}}$, Patrick Kestemont ${ }^{\mathrm{a}, *}$ \\ ${ }^{a}$ Research Unit in Environmental and Evolutionary Biology (URBE), Institute of Life, Earth and Environment (ILEE), University of Namur, Belgium \\ ${ }^{\mathrm{b}}$ Pharmacology Department, Hanoi University of Pharmacy, Viet Nam \\ ${ }^{\mathrm{c}}$ Unit of Therapeutic Chemistry and Pharmacognosy, University of Mons, Belgium \\ ${ }^{\mathrm{d}}$ Faculty of Fisheries and Aquaculture, Vietnam National University of Agriculture (VNUA), Hanoi, Viet Nam \\ ${ }^{\mathrm{e}}$ Dept. Life Sciences, GIGA-R, Lab. for Organogenesis and Regeneration, University of Liege, Belgium \\ ${ }^{\mathrm{f}}$ Department of Pharmacology and Clinical Pharmacy, School of Medicine and Pharmacy, Vietnam National University, Viet Nam
}

\section{A R T I C L E I N F O}

\section{Keywords:}

RAW 264.7

Zebrafish

RBC membrane stabilization

Nitric oxid

Anti-inflammatory

Clerodendrum cyrtophyllum

\begin{abstract}
A B S T R A C T
Ethnopharmacological relevance: Clerodendrum cyrtophyllum Turcz, a plant belonging to the Verbenaceae family, has been used in traditional medicine for the treatment of various inflammatory diseases in many Asian countries.

Aim of the study: The study aimed to evaluate anti-inflammatory properties of the ethanol extract from Clerodendrum cyrthophyllum Turcz leaves (EE-CC) through in vitro and in vivo models.

Material and methods: Total phenolic and flavonoid contents in the extract were determined using colorimetric methods and HPTLC. In red blood cell membrane stabilization model, rat erythrocyte suspension was treated with crude ethanol extract at different concentrations, the hemoglobin content of the supernatant solution released by red blood hemolysis was estimated. We also evaluated the effects of the ethanol extract from this plant on the production of nitric oxide (NO), tumor necrosis factor alpha (TNF- $\alpha$ ) in stimulated RAW 264.7 cells. In order to elucidate its anti-inflammatory molecular mechanisms, we further evaluated the effects of the EE-CC on the expression of the inflammatory genes in inflammation-induced zebrafish model by tail-cutting using qPCR analysis.

Results: Colorimetric methods and HPTLC revealed high phenolic and flavonoid contents in the extract. In the red blood cell membrane stabilization model, the amount of hemoglobin released by red blood hemolysis significantly decreased in the presence of EE-CC, demonstrating a strong membrane stabilizing activity. EE-CC did not cause any toxic effect on cell viability but strongly inhibited NO and TNF-a release due to LPS induction. The association with EE-CC significantly reduced the expression of cox-2, pla2, c3a, il-1(il1fma), il-8 (cxcl8b.1), tnf- $\alpha$, and $n f-k b$, while increased the expression of the anti-inflammatory cytokine il-10 gene in cut-tail induced inflammation of zebrafish model.

Conclusions: Taken together, the results suggest that the raw ethanol extract from C. cyrtophyllum Turcz leaves presents potent anti-inflammatory activities and may be useful for the treatment of various inflammatory diseases.
\end{abstract}

\section{Introduction}

Inflammation is the protective response of the body against infectious agents and injury, allergic or chemical irritation by removing injurious stimuli and initiating the healing process. Two important components taking part of the inflammation process include cells of the immune system and inflammatory mediators that come from these cells or plasma proteins. Cells of the immune system are mast cells,

Abbreviations: EE-CC, the ethanol extract from Clerodendrum cyrthophyllum Turcz leaves; NO, nitric oxide; TNF- $\alpha$, tumor necrosis factor alpha; LPS, lipopoly-

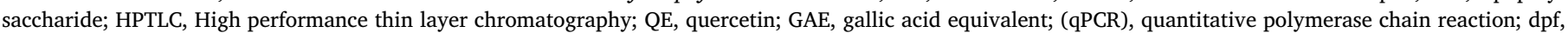
day post fertilization; RBC, red blood cell

${ }^{*}$ Corresponding author. University of Namur, Research Unit in Environmental and Evolutionary Biology (URBE), Institute of Life, Earth and Environment (ILEE), 61 Rue de Bruxelles, 5000, Namur, Belgium.

E-mail address: Patrick.kestemont@unamur.be (P. Kestemont). 
neutrophils and monocytes/macrophages, $\mathrm{T}$ cells and $\mathrm{B}$ cells. Inflammatory mediators include: nitric oxide, prostaglandins, leukotrienes, vasoactive amines (histamine, serotonin), and cytokines, proteases, chemokines. In response to injurious stimuli, the body initiates a chemical signaling cascade that stimulates responses to repair the damage. Inflammatory pathways are activated. These signals activate the immune cell chemotaxis from the general circulation to the sites of injury. These activated cells produce chemical mediators that bind to specific target receptors on the cells and induce the characteristic signs of inflammation (swell, heat, red, pain and loss of function) (Chen et al., 2018). Usually, cellular and molecular events in acute inflammatory responses can lead to recovery from infection and to healing. However, if the acute inflammation is not controlled or resolved, inflammation cascades can lead to the development of a variety of chronic inflammatory diseases such as asthma, rheumatoid arthritis, multiple sclerosis, inflammatory bowel disease and psoriasis, diseases of the cardiovascular, metabolic.

Lysosomal enzymes released during inflammation produce a variety of disorders leading to tissue injury, by macromolecules damaging and membranes peroxidation. Stabilization of the lysosomal membrane thus has an important role in inhibiting the release of lysosomal constituents from activated neutrophils and limit the inflammatory response (Seema Chaitanya Chippada et al., 2011).

Macrophages are the main pro-inflammatory cells, playing critical roles in immune reactions, allergy, inflammation, and protecting the organism from external intruders through phagocytosis. Upon activation, macrophages become potent secretory cells that release large amounts of pro-inflammatory mediators including NO, prostaglandins and the cytokines TNF- $\alpha$, IL-1 $\beta$, and IL-6 (Shao et al., 2013). Production of NO and prostaglandins are regulated by iNOS and COX-2. Overproduction of NO can trigger some inflammatory diseases such as heart attacks, septic shocks, rheumatoid arthritis (Jung et al., 2014). NF-кB is a transcription factor that plays an important role in the transcription of genes, which are involved in immune and inflammatory responses. Upon stimulation, NF- $\mathrm{KB}$ is liberated from a complex with $\mathrm{I}-\mathrm{\kappa B}$, now becoming enabled to migrate to the nucleus where it binds to the cisacting $\mathrm{\kappa B}$ enhancer element of target genes and induces transcription of its target genes such as COX-2, iNOS, TNF- $\alpha, I L-1 \beta$, and $I L-6$, chemokines and adhesion molecules (Karin and Ben-neriah, 2000). Inhibition of the production and/or release of many of these mediators are wellestablished targets for the discovery of anti-inflammatory drugs, with nonsteroidal anti-inflammatory drugs (NSAIDs) as COX-inhibitors being the most prominent drug class. However, due to the various side effects associated with many NSAIDs, especially gastrointestinal irritation and increased risk of myocardial infarction and stroke, there is still an immense need for anti-inflammatory agents with a better benefit-risk profile (Pompermaier et al., 2018). For this purpose, ethnobotanical studies represent an increasingly attractive approach for applying indigenous knowledge of plant use to modern societies, with the final aim of developing new remedies.

Clerodendrum cyrtophyllum Turcz, a plant belonging to the Verbenaceae family, is widely distributed in Vietnam, China, India, Japan, Korea and Thailand (Kar et al., 2014). In Vietnam, the plant is called "Bọ mẩy". In Vietnam and China, it has been used for the treatment of some diseases such as inflammation of the throat, rheumatic arthritis, colds, high fever, migraines (Zhou et al., 2013). In several studies, phenolic acids, polyketides, diterpenes, triterpenes, glycosides, proteins, sterols and flavonoids have been isolated, and (poly)phenols are the major constituents of the plant (Zhou et al., 2013). Among the phytochemical compounds isolated from this plant, the glycosidated coumaramide compound clerodendiod B was shown to have potent activity in inhibiting the NF-kB pathway (Wang et al., 2012). Total phenols and flavonoids displayed high antioxidant activity and potential anti-inflammatory activity in several experimental models (Liu et al., 2011). However, underlying mechanisms remain uncertain.
In this study, we investigated the anti-inflammatory effects and the underlying molecular mechanisms of the ethanol extract from Clerodendrum cyrtophyllum Turcz on different biological models. For simple, fast and inexpensive testing, we selected the rat red blood cell membrane stabilization model by measuring hemoglobin release, as well as activated RAW264.7 macrophage cells to measure survival, NO production, and TNF- $\alpha$ secretion. Among animal models, zebrafish has the advantage to display pathological features of inflammation similar to those of humans. This fish model has been established as an ideal model for studying the pathophysiology of human inflammatory-related diseases (Yang et al., 2014). To complement the preliminary in vitro cellular tests, we chose the zebrafish larva as an alternative to animal testing (Saeidnia et al., 2015) to confirm the anti-inflammatory effects of the ethanol extract as well as to elucidate the molecular mechanisms of its effects.

\section{Materials and methods}

\subsection{Chemicals}

RPMI 1640, fetal bovine serum (FBS), penicillin and streptomycin were purchased from Hyclone (Thermo Scientific, Waltham, MA, USA). Mouse TNF- $\alpha$ ELISA kits were purchased from Abcam (ab208348, Cambridge, CB20AX, UK). LPS (Escherichia coli 0111.B4), 3-(4,5-dimethylthiazol-2-yl)-2,5-diphenyltetrazolium bromide (MTT), sulfanilamide (S9251-100G), phosphoric acid and naphthyl ethylenediamine dihydrochloride (N9125-10G) were purchased from Sigma Chemical Co. (St. Louis, MO, USA). All other reagents were of the highest commercially available grade.

\subsection{Cell culture}

RAW 264.7 cells, a murine macrophage cell line, were obtained from American Type Cell Culture (ATCC; Rockville, MD) and cultured in RPMI 1640 medium supplemented with $10 \%$ fetal bovine serum (FBS), penicillin $(100 \mathrm{U} / \mathrm{ml})$, and streptomycin $(100 \mu \mathrm{g} / \mathrm{ml})$ at $37{ }^{\circ} \mathrm{C}$ in an incubator containing $5 \% \mathrm{CO}_{2}$.

\subsection{Preparation of the ethanol extract of Clerodendrum cyrtophyllum (EE-} CC)

Plant collection: Leaves of Clerodendrum cyrtophyllum Turcz were collected from Northern provinces in Vietnam during June, 2018 by Dr Nguyen Kim Thanh, from Vietnam National University (VNU-BIOL). An official herbarium number (HNU 024106) was deposited at Botanical Museum of Hanoi, University of Science. Leaves were cleaned, dried for $72 \mathrm{~h}$ to a constant weight using a hot air oven at $40{ }^{\circ} \mathrm{C}$ and ground in a blender to fine powder (size smaller than $0.5 \mathrm{~mm}$ ).

Preparation of total extract: Given that polar (aqueous) extracts are used in traditional practice, we selected ethanol to extract polar secondary metabolites, minimizing the extraction of mineral salts and polysaccharides. Hundred $g$ dried leaves powder were extracted with $1000 \mathrm{ml} \mathrm{95 \%}$ ethanol, at $60{ }^{\circ} \mathrm{C}$ in a water bath with $360 \mathrm{rpm}$ agitation for $4 \mathrm{~h}$. The extract was then filtered and collected. The residue was extracted for another two times using the same procedure. The collected ethanol extracts were then combined, concentrated on a rotary evaporator $\left(40{ }^{\circ} \mathrm{C}\right)$ under reduced pressure and lyophilized to obtain the crude extract. The yield of extract was $11.3 \%$ relative to the dried leaves powder. The crude extract was stored at $-20{ }^{\circ} \mathrm{C}$ until use.

\subsubsection{Determination of total phenolics and flavonoids content}

The extract total phenolic content was determined spectrophotometrically according to the Folin-Ciocalteu colorimetric method of Dorman et al. (2003) (Dorman et al., 2003). The total phenolics content was expressed as mg gallic acid equivalents (GAE mg/g) using the following equation based on the calibration curve: $y=0.0013 x$ - 
$0.0062\left(\mathrm{R}^{2}=0.995\right)$, where $\mathrm{y}$ was the absorbance and $\mathrm{x}$ the gallic acid concentration $(\mu \mathrm{g} / \mathrm{mL})$. Data presented are the average of three independent measurements, expressed in dry weight of leaves.

The extract flavonoids content was determined spectrophotometrically using a method based on the formation of a complex flavonoid-aluminum (Fatiha et al., 2012). The total flavonoids content was calculated as quercetin $(\mathrm{QE} \mathrm{mg} / \mathrm{g}$ ) equivalents using the following equation based on the calibration curve: $\mathrm{y}=0.042 \mathrm{x}+0.1188$ $\left(\mathrm{R}^{2}=0.990\right)$ where $\mathrm{y}$ was the absorbance and $\mathrm{x}$ the quercetin concentration $(\mu \mathrm{g} / \mathrm{mL})$. Data presented are the average of three independent measurements, expressed in dry weight of leaves.

\subsubsection{High performance thin layer chromatography (HPTLC) profiling}

HPTLC was performed according to the procedure of the European Pharmacopeia 10 (Europe, 2019) using Camag Automatic TLC Sampler (ATS 4), Automatic Developing Chamber 2 (ADC 2), Derivatizer and TLC Visualizer 2, systems operated under the software VisionCATS version 2.5. The HPTLC profiling of phenolic compounds/flavonoids was performed on silica gel 60 F254 HPTLC plates (Merck, Germany), using ethyl acetate - methylethylketone - formic acid - water $5: 3: 1: 1$, $\mathrm{v} / \mathrm{v} / \mathrm{v} / \mathrm{v}$ ) as a solvent system; after being heated at $100{ }^{\circ} \mathrm{C}$ for $3 \mathrm{~min}$, the plates were sprayed with a $1 \% \mathrm{MeOH}$ solution of aminoethanol diphenyl borate and $5 \% \mathrm{MeOH}$ solution of macrogol 400 and visualized under UV $365 \mathrm{~nm}$ and visible light.

The HPTLC profiling of iridoids was performed on silica gel 60 F254 HPTLC plates (Merck, Germany). Ethyl acetate - methanol - water $(77: 25: 8 \mathrm{v} / \mathrm{v} / \mathrm{v})$ was used as a solvent system; plates were sprayed with a solution of vanillin (1\%) and sulfuric acid (2\%) in EtOH, heated for $5 \mathrm{~min}$ at $100{ }^{\circ} \mathrm{C}$ and visualized under UV $365 \mathrm{~nm}$ and visible light.

\subsubsection{HPLC-DAD-ESI-MS analysis}

High performance liquid chromatography analysis with diode array and MS detection (HPLC-DAD-ESI-MS) was performed on the extracts. LC-DAD analysis was carried out on an Agilent 1260 Infinity II system connected to an Advion expression L mass spectrometer via an electrospray ionization (ESI) interface. Chromatographic separations were achieved at a constant flow rate of $1.2 \mathrm{~mL} / \mathrm{min}$ on a Agilent InfinityLab Poroshell 120 EC-C18 column $(4.6 \times 100 \mathrm{~mm} ; 4 \mu \mathrm{m})$ maintained at $32{ }^{\circ} \mathrm{C}$. A gradient elution was performed with mobile phases A (Acetonitrile) and B (Water - $0.1 \%$ formic acid) as follows: $0 \mathrm{~min}, 5 \%$ A; $2 \mathrm{~min}, 5 \% \mathrm{~A} ; 30 \mathrm{~min}, 30 \% \mathrm{~A} ; 60 \mathrm{~min}, 80 \% \mathrm{~A} ; 75 \mathrm{~min}, 100 \% \mathrm{~A}$. Using a post-column passive splitter, a $0.2 \mathrm{~mL} / \mathrm{min}$ flow rate was delivered into the mass spectrometer ionization source. DAD detection wavelengths were set at 254, 270 and 330 with peak scanning between 200 and $700 \mathrm{~nm}$. Full scan mass spectra were registered in negative and positive modes between 100 and $1000 \mathrm{~m} / \mathrm{z}$. Chromatographic and mass spectrometry data were acquired and processed using the instrument built-in software.

\subsubsection{Fish and experimental conditions}

The adult wild - type $\mathrm{AB}$ zebrafish (Danio rerio) were maintained in a recirculating ZebTec housing system (Techniplast) at $28{ }^{\circ} \mathrm{C}$ with a 12:12 h (light/dark) photoperiod. Conductivity was maintained at approximately $500 \mu \mathrm{S} / \mathrm{cm}, \mathrm{pH}$ at 7.2 . Fish were fed ad libitum three times daily. The day before mating, males and females (2:2) were placed in spawning tanks. Naturally spawned embryos were obtained within $30 \mathrm{~min}$ after the lights were switched on in the morning. The embryos were selected visually using a binocular microscope and only fertilized and normally developed eggs were selected. Selected eggs were placed in embryo medium (clean water from housing system) at $28^{\circ} \mathrm{C}$. Embryo medium was renewed every $24 \mathrm{~h}$. Hatched larvae (at $4 \mathrm{dpf}$ ) were used for subsequent experiments. The use of zebrafish was in accordance with the animal welfare act. Since zebrafish larvae below $120 \mathrm{~h}$ old are not considered animals (Lackmann et al., 2018) and hence no animal test authorization is required according to European legislation (EU Directive, 2010/63/EU). All experiments were terminated at $120 \mathrm{hpf}$.
The term "larvae" refers to hatched embryos up to $120 \mathrm{hpf}$ that are using up the yolk-sac reserves and still do not feed externally (also called yolk-sac larva, early larva, pre-larva or eleuthero embryo) (Lackmann et al., 2018).

\subsection{Experimental design}

\subsubsection{Preparation of test samples}

Dry ethanol extract was dissolved in DMSO to make a stock solution of $50 \mathrm{mg} / \mathrm{mL}$. Depending on the experiment type, the stock solution was diluted to different concentrations using $\mathrm{NaCl} 0.9 \%$ with heat-induced hemolysis experiments, RPMI medium for experiments using RAW 264.7 cells, or in fresh larvae medium to the final concentration in each experiment well to be $5,20,25,40,50,80,100,200,500 \mu \mathrm{g} / \mathrm{ml}$.

2.4.1.1. In vitro experiments heat-induced hemolysis. The heat-induced hemolysis of erythrocytes was carried out as described by Ranasinghe et al. (2012) (Ranasinghe et al., 2012) with some modifications. Fresh rat blood was collected and transferred to heparinized centrifuge tubes. The tubes were centrifuged at $3000 \mathrm{rpm}$ for $10 \mathrm{~min}$, and the resultant erythrocyte pellet washed three times with equal volume of $\mathrm{NaCl} 0.9 \%$. Final erythrocyte pellet was suspended in $\mathrm{NaCl} 0.9 \%$ to make a $10 \%$ suspension containing $10 \% \mathrm{v} / \mathrm{v}$ of RBCs in $\mathrm{NaCl} 0.9 \%$.

Various concentrations of ethanol extract from Clerodendrum cyrtophyllum Turcz (EE-CC at 500, 200, 100, 50 and $25 \mu \mathrm{l} / \mathrm{ml}$ ) were prepared. The test mixture consisted of $20 \mu \mathrm{L}$ of the sample, $60 \mu \mathrm{L} \mathrm{NaCl} 0.9$ $\%, 20 \mu \mathrm{L} 10 \mathrm{mM}$ sodium phosphate buffer $\mathrm{pH} 7.4,100 \mu \mathrm{L}$ of the $10 \%$ RBC suspension in test tubes. Sodium diclofenac $(600 \mu \mathrm{g} / \mathrm{ml})$ was used as positive control (Seema Chaitanya Chippada et al., 2011) (Begum et al., 2016). DMSO was used as control. The concentration of DMSO in control group was the same as in all other groups. The reaction mixture was incubated at $55{ }^{\circ} \mathrm{C}$ for $20 \mathrm{~min}$. After heating, the reaction mixtures were centrifuged at $5400 \mathrm{rpm}$ for $5 \mathrm{~min} .100 \mu$ lof supernatant were collected. Hemoglobin content of the supernatant solution was measured indirectly through its absorbance (O.D.) at $540 \mathrm{~nm}$ using a microplate reader (Epoch biotek plate reader). The blank was prepared as above, except that the reaction mixture was incubated at $4{ }^{\circ} \mathrm{C}$. The percent inhibition of hemolysis or percent of protection from hemolysis was calculated using the following formula:

$\%$ protection $=\frac{(\text { Control OD }- \text { Blank OD })-(\text { Sample OD }- \text { Blank OD })}{\text { Control OD }- \text { Blank OD }}$

$x 100$

\subsubsection{Cell culture preparation}

The RAW 264.7 cells were seeded in 96-well culture plates with $1 \times 10^{5}$ cells/well and incubated for $24 \mathrm{~h}$ at $37{ }^{\circ} \mathrm{C}$ in an incubator containing $5 \% \mathrm{CO}_{2}$. The cells were pretreated with various concentrations $(12.5,25,50,100$ and $200 \mu \mathrm{g} / \mathrm{mL})$ of EE-CC or of indomethacin $100 \mu \mathrm{g} / \mathrm{ml}$ (positive control) for $1 \mathrm{~h}$ (Lee and Park, 2016) (Sudsai and Wattanapiromsakul, 2013). DMSO was used as control. The concentration of DMSO in the control group was the same as in all other groups. The cells were stimulated with or without LPS $(1 \mu \mathrm{g} / \mathrm{mL})$ at $37{ }^{\circ} \mathrm{C}$ for $24 \mathrm{~h}$. After a $24 \mathrm{~h}$ incubation at $37{ }^{\circ} \mathrm{C}, 100 \mu \mathrm{l}$ of supernatant were collected for the nitric oxide (NO) assay and $50 \mu$ l for the TNF- $\alpha$ assay. The remaining cells were used for assessing cell viability using the MTT assay.

\subsubsection{Nitric oxide (NO) assay}

The amount of nitric oxide (NO) in the culture medium was measured by the Griess reaction (Fabiola et al., 2016). Briefly, $100 \mu \mathrm{L}$ of cell culture medium were mixed with $100 \mu \mathrm{L}$ of Griess reagent (equal volumes of $1 \%(\mathrm{w} / \mathrm{v})$ sulfanilamide in $5 \%(\mathrm{v} / \mathrm{v})$ phosphoric acid, and $0.1 \%(\mathrm{w} / \mathrm{v})$ naphthyl ethylenediamine dihydrochloride). The reaction mix was incubated at room temperature for $10 \mathrm{~min}$, the absorbance at $540 \mathrm{~nm}$ was measured using a microplate reader (Epoch biotek plate 
Table 1

Primers pairs used in this study.

\begin{tabular}{|c|c|c|c|}
\hline Gene name & Product length & GenBank Accession No. & Forward and reverse primer sequences $\left(5^{\prime}-3^{\prime}\right)$ \\
\hline \multirow[t]{2}{*}{ ß-actin } & 193 & AF057040 & Fwd: CCCCATTGAGCACGGTATTG \\
\hline & & & Rev: ATACATGGCAGGGGTGTTGA \\
\hline \multirow[t]{2}{*}{ efl1- $\alpha$} & 150 & L23807.1 & Fwd: CCAAGGAAGTCAGCGCATAC \\
\hline & & & Rev: CCTCCTTGCGCTCAATCTTC \\
\hline \multirow[t]{2}{*}{ Interleukin-1 il-1 (il1fma) } & 185 & NM_001290418.1 & Fwd: AGGAGCGAACAGTCATGAGT \\
\hline & & & Rev: ACAACCTCGAGCTACAACCA \\
\hline \multirow[t]{2}{*}{ Interleukin -8 il-8 (cxcl8b.1) } & 234 & NM_001327985.1 & Fwd: GCCTTCATGCTTCTGATCTGC \\
\hline & & & Rev: AATCACCCACGTCTCGGTAGGA \\
\hline \multirow{2}{*}{ Cyclooxygenase- 2 (ptgs $2 a$ or $\operatorname{cox} 2$ ) } & 240 & NM_153657.1 & Fwd: ACAGATGCGCTACCAGTCTT \\
\hline & & & Rev: CCCATGAGGCCTTTGAGAGA \\
\hline \multirow[t]{2}{*}{ inos (nos $2 a)$} & 206 & NM_001104937.1 & Fwd: GCATTTGGAGACGGAGGTTC \\
\hline & & & Rev: TGACCTTGCATCTCCGAAGT \\
\hline \multirow[t]{2}{*}{ Phospholipase A2 pla2 (pla2g4aa) } & 177 & NM_131295.2 & Fwd: TCATGTCTCCTGGGCTGTTT \\
\hline & & & Rev: CCAGCTCСTCCTCCATAGTG \\
\hline \multirow[t]{2}{*}{ Tumor necrosis factor (tnfa) } & 227 & AB183467 & Fwd: CACAAAGGCTGCCATTCACT \\
\hline & & & Rev: GATTGATGGTGTGGCTCAGGT \\
\hline \multirow[t]{2}{*}{$n f-k b(n k a p)$} & 210 & NM_001003414.1 & Fwd:GGTCGGACAGAGATCACGGATT \\
\hline & & & Rev: TGCTGTTCTTCACGTCCTCT \\
\hline \multirow[t]{2}{*}{ Interleukin-10 (il-10) } & 100 & AY887900.1 & Fwd: AGTCATCCTTTCTGCTCTGCT \\
\hline & & & Rev: AAAGCCCTCCACAAATGAGC \\
\hline \multirow[t]{2}{*}{$c 3 a(c 3 a .1)$} & 235 & NM_131242.1 & Fwd: GTACGAGGCGAACAACTGGA \\
\hline & & & Rev: CATCATACGCCGCAGCTTTC \\
\hline \multirow[t]{2}{*}{ lysozyme } & 236 & BC162644.1 & Fwd: TCAGCTGATACGGGGAAGGA \\
\hline & & & Rev: CCTTTTACCCAGCGGGACAT \\
\hline \multirow[t]{2}{*}{ vcam (vcam1b) } & 153 & NM_001083835.1 & Fwd: GCTAAGCAGGGTTGTGGATG \\
\hline & & & Rev: TCCAGACTGTCGCTGTGATT \\
\hline \multirow[t]{2}{*}{ mpo } & 152 & AF349034.1 & Fwd: GTGGTCGTGTCGGTTCTCTT \\
\hline & & & Rev: GCAGATTATGCGGGCCATTG \\
\hline
\end{tabular}

reader). The concentration of NO in the samples was calculated according to a standard curve of sodium nitrite. Fresh culture medium was used as blank in all experiments.

Measurement of cytokines (TNF- $\alpha$ ): The levels of TNF- $\alpha$ in the culture medium (supernatant) were measured with enzyme-linked immunosorbent assay (ELISA) kit (Abcam) in accordance with the manufacturer's protocols. The absorbance was measured at $540 \mathrm{~nm}$ using a microplate reader. The concentrations of TNF- $\alpha$ were calculated according to the standard curve using each of the recombinant cytokines in the ELISA kits.

\subsubsection{MTT assay}

Cell viability was assessed by MTT assay. After collecting the supernatant for NO and TNF- $\alpha$ assay, the remaining cells in each well were incubated with $100 \mu \mathrm{L}$ medium containing MTT $(500 \mu \mathrm{g} / \mathrm{mL})$ for $4 \mathrm{~h}$ at $37{ }^{\circ} \mathrm{C}$. Viable cells with active metabolism convert MTT into a purple colored formazan product. The medium was discarded, and the formazan was dissolved with $100 \mu \mathrm{l}$ DMSO by shaking for $5 \mathrm{~min}$. The absorbance of each well at $540 \mathrm{~nm}$, measured using a microplate reader (Epoch biotek plate reader), was considered directly proportional to the number of viable cells.

\subsubsection{In vivo experiments}

2.4.4.1.1. The toxicity screening test. Four-days post fertilization (dpf) wild-type zebrafish larvae were treated with EE-CC diluted in fresh embryo medium at different final concentrations $(0,5,20,40$, and $80 \mu \mathrm{g} / \mathrm{mL}$ ) for $2,8,14,24 \mathrm{~h}$. Treatments were performed in triplicate (20 larvae per group per dose). After incubation, larvae were observed for mortality. At non-lethal EE-CC concentrations, larvae were collected, washed and analysed using qPCR to evaluate the effects of EE-CC on immune gene expression. Only EE-CC concentrations having no or low immunotoxicity were selected for further experiments.

2.4.4.1.2. In vivo anti-inflammatory test in cut tail zebrafish larval model. Four-days post fertilization (dpf) wild-type zebrafish larvae were anesthetized with ice slush (ice and water admixture) (Chen et al., 2013). After anesthesia, to trigger tail-cutting-induced inflammation, the tail of the zebrafish larvae was cut, around $0.5 \mathrm{~mm}$
( $\pm 0.2 \mathrm{~mm}$, tolerated range) from the tip of each larval tail (Lee et al., 2013) (Cordero-maldonado et al., 2013). To make wounds as consistently sized as possible, tail-cutting was performed using a blade (Swann -Morton Stainless steel surgical blade BS2982 ISO7740) under a microscope. As soon as tail-cutting was completed, the zebrafish larvae were transferred into fresh larvae medium. Zebrafish larvae were randomly divided into groups, 20 larvae/well, 3 wells for a treatment. The zebrafish larvae were treated with dexamethasone $5 \mu \mathrm{g} /$ $\mathrm{ml}$, or EE-CC diluted in fresh embryo medium at different final concentrations (selected from the toxicity screening test) for $24 \mathrm{~h}$. DMSO was used as control. The concentration of DMSO in the control group was the same as in all other groups. After $24 \mathrm{~h}$, zebrafish larvae were collected, frozen and stored in $-80{ }^{\circ} \mathrm{C}$ for qPCR analysis.

\subsubsection{Quantitative PCR}

2.4.5.1. Total RNA extraction and reverse transcription. Total RNA was extracted from these larvae using Trizol Reagent solution (Ambion, Thermofisher Scientific) following the manufacture's instructions. The pellet containing RNA was dried and resuspended in $100 \mu \mathrm{l}$ of RNasefree water. The concentration of total RNA was determined spectrophotometrically at $\mathrm{A}_{260} / \mathrm{A}_{280}$ and $\mathrm{A}_{260} / \mathrm{A}_{230} \mathrm{~nm}$ using a NanoDrop $^{\mathrm{TM}} 1000$ (Thermo Scientific). RNA integrity was checked by gel electrophoresis (1.2\% agarose). The extracted RNA samples were then subjected to DNase treatment (DNA-free ${ }^{\mathrm{TM}}$ DNA Removal KitInvitrogen) to avoid genomic DNA contamination. $1 \mu \mathrm{g}$ total RNA was reverse-transcribed into double-stranded cDNA using the RevertAid RT kit (Thermo Scientific) according to the manufacturer's instructions.

The resulting cDNA was used to measure the expression of $12 \mathrm{im}$ mune system genes in a real-time quantitative polymerase chain reaction (qPCR). The mean expression of two housekeeping genes ( $ß$-actin, elongation factor $1 \alpha E F 1 \alpha$ ) were used as the reference. The expression of genes encoding antibacterial protein (lysozyme), pro-inflammatory cytokines (il-1(il1fma), il-8 (cxcl8b.1), tnf- $\alpha$ ), neutrophil (mpo), complement 3a (c3a), phospholipase A2 (pla2), cox-2, nitric oxide synthase (inos), transcription factor NF- $\kappa \mathrm{B}$ (nf-kb), vascular cell adhesion molecule (vcam) and an anti-inflammatory response cytokine (il-10) was evaluated. The list of specific primers used is given in Table 1. Primers 
were designed on Primer3 software. Amplifix software was used to check the quality of the primers. The efficiency of each primer was confirmed by RT-PCR.

RT-PCR was performed using an ABI Step One Plus Real Time PCR system (Applied Biosystems). Five (5) $\mu$ l of 25-fold diluted cDNA template was mixed with $5 \mu \mathrm{l}$ of each primer $(5 \mu \mathrm{M})$ and $10 \mu \mathrm{l}$ of SYBR green PCR master mix (Applied Biosystems) in a final volume of $20 \mu \mathrm{l}$. The standard cycling conditions were $95^{\circ} \mathrm{C}$ for $10 \mathrm{~min}$, followed by 40 cycles of $95{ }^{\circ} \mathrm{C}$ for $30 \mathrm{~s}$ and $60{ }^{\circ} \mathrm{C}$ for $30 \mathrm{~s}$. All reactions were performed as technical triplicates. For analysis, a standard curve of a pool of the cDNA of all samples was constructed following the absolute quantification method (Bio-Rad (2006). The equation for the linear regression line $\mathrm{CT}=\mathrm{m}(\log$ quantity $)+\mathrm{b}$. Where $\mathrm{b}$ is the $\mathrm{y}$-intercept and $\mathrm{m}$ is the slope of the linear regression. Based on the equation for the linear regression, we can determine the quantity of an unknown sample:

Quantity $=10^{(C T-b) / m}$

The ratios of the quantity of candidate gene /average quantity of 2 housekeeping genes were subsequently calculated for each candidate gene and used to assess the differences in expression levels between experimental groups.

\subsection{Data presentation and statistical analyses}

Data analyses were performed using SPSS software version 16.0. Results are presented as the means \pm S.E.M of at least three independent experiments. Datas followed a normal distribution. Therefore in this case, statistical significance was determined by oneway analysis of variance ANOVA followed by LSD's multiple comparison test to determine treatment differences. Differences were considered statistically significant when $p$ values were $<0.05$. For in vitro experiments, concentration providing $50 \%$ inhibition (IC50) was calculated by non-linear regression using GraphPad Prism Software (San Diego, CA, USA).

\section{Results}

\subsection{Total phenolic and flavonoid contents}

The ethanolic extract of $C$. cyrtophyllum leaves (EE-CC) presented a concentration of total phenolic compounds of $23.3 \pm 1.5 \mathrm{GAE} \mathrm{mg} / \mathrm{g}$ expressed in dry weight of leaves material. Flavonoids content was evaluated at $2.97 \pm 0.01 \mathrm{QE} \mathrm{mg} / \mathrm{g}$ expressed in dry weight of leaves material.

\subsection{HPTLC profiling}

The phenolic compounds/flavonoids (Fig. 1A) and iridoids (Fig. 1B) of EE-CC were profiled by HPTLC and visualized under UV $365 \mathrm{~nm}$ and visible light after derivatization. Such characteristic profiles will allow to control the identification of further plant samples; the formal identification of major bands however requires comparison with reference compounds described in the literature; to our best knowledge, these are not commercially available. Further work in HPLC-DAD-MS yielded 3 major peaks but no characteristic m/z could be identified (Fig. 2).

\subsection{In vitro experiments}

3.3.1. Effect of the ethanol extract from the leaves of C. cyrtophyllum (EECC) on hemolysis of red blood cells induced by heat

Heating the assay units at $55{ }^{\circ} \mathrm{C}$ induced $100 \%$ hemolysis in the control samples. The $\mathrm{NaCl} 0.9 \%$ control caused a very weak protection $0.5 \%$, while the samples treated with diclofenac experienced were protected to $78 \%$ (Fig. 3). Addition of the ethanol extract from C. cyrtophyllum caused a concentration-dependent stabilization of the red blood cell membranes. At the highest concentration of $500 \mu \mathrm{g} / \mathrm{ml}$, EE-

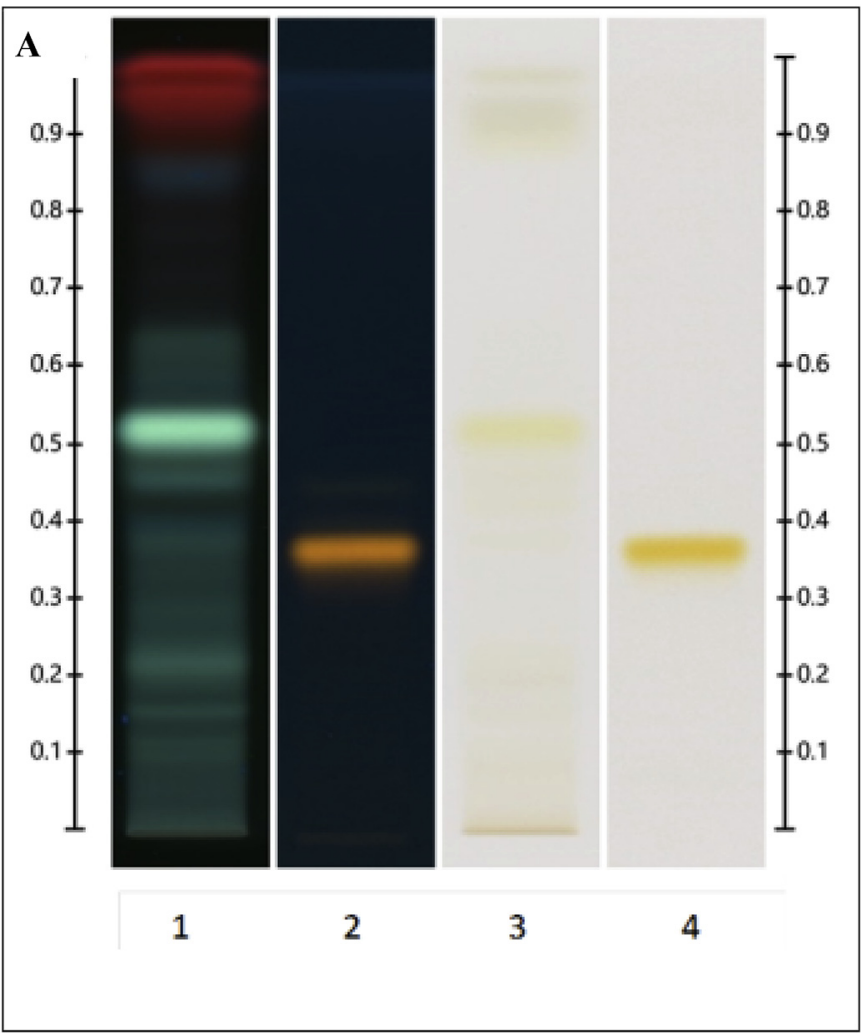

Fig. 1. aHPTLC profile of ethanolic extract (1 and 3) of Clerodendrum cyrtophyllum leaves (EE-CC) and rutin (2 and 4). Analysis was performed on silica gel 60 F254 HPTLC plates (Merck, Germany), using ethyl acetate - methylethylketone - formic acid - water (5:3:1:1, v/v/v/v) as a solvent system; plates were sprayed with a $1 \% \mathrm{MeOH}$ solution of aminoethanol diphenylborate and $5 \%$ $\mathrm{MeOH}$ solution of macrogol 400 after being heated at $100{ }^{\circ} \mathrm{C}$ for $3 \mathrm{~min}$ and visualized under UV $365 \mathrm{~nm}$ (1 and 2) and visible light (3 and 4).

CC inhibited $93 \%$ of hemolysis. At the concentrations of 200, 100, 50, $25 \mu \mathrm{g} / \mathrm{ml}$, the $\%$ inhibition of hemolysis was, respectively $81 ; 56 ; 36$ and $22 \%$ (Fig. 3). No significant differences were observed between EECC 200 and $500 \mu \mathrm{g} / \mathrm{ml}$, between EE-CC 50 and $100 \mu \mathrm{g} / \mathrm{ml}$ in inhibition of hemolysis. However, EE-CC $200 \mu \mathrm{g} / \mathrm{ml}$ was more potent than EE-CC 50 and $100 \mu \mathrm{g} / \mathrm{ml}$. The IC50 of EE-CC on hemolysis was found to be $75 \mu \mathrm{g} / \mathrm{ml}$, compared with diclofenac $294 \mu \mathrm{g} / \mathrm{ml}$ (Table 2). Thus, the effect of EE-CC on red blood cell membrane stabilization was even higher than the positive control diclofenac.

\subsubsection{Effect of the ethanol extract from leaves of C. cyrtophyllum (EE-CC)} on cell viability and NO production of LPS-induced RAW 264.7 macrophages

As shown in Fig. 4A, RAW 264.7 cells treated with LPS alone dramatically increased NO release as compared with the non-treated cells, while indomethacin inhibited this increase. EE-CC inhibited NO production in a dose-dependent manner. No significant differences were observed between EE-CC 12.5 and $25 \mu \mathrm{g} / \mathrm{ml}$, between EE-CC 50 and $100 \mu \mathrm{g} / \mathrm{ml}$ in inhibition of NO production. However, EE-CC $50 \mu \mathrm{g} / \mathrm{ml}$ was more potent than EE-CC 12.5 and $25 \mu \mathrm{g} / \mathrm{ml}$ and EE-CC $200 \mu \mathrm{g} / \mathrm{ml}$ was more potent than EE-CC 50 and $100 \mu \mathrm{g} / \mathrm{ml}$ at reducing NO production. The IC50 value of EE-CC on NO release was found to be $48 \mu \mathrm{g} /$ $\mathrm{ml}$, compared with indomethacin $47 \mu \mathrm{g} / \mathrm{ml}$ (Table 3 ).

The effect of EE-CC on the viability of activated RAW 264.7 cells was studied using MTT assay. No toxic effects were observed in presence of EE-CC at concentrations up to $200 \mu \mathrm{g} / \mathrm{ml}$ after $24 \mathrm{~h}$ LPS treatment. Interestingly, it seems that the extract protects from LPSinduced cell death. (Fig. 4B). 


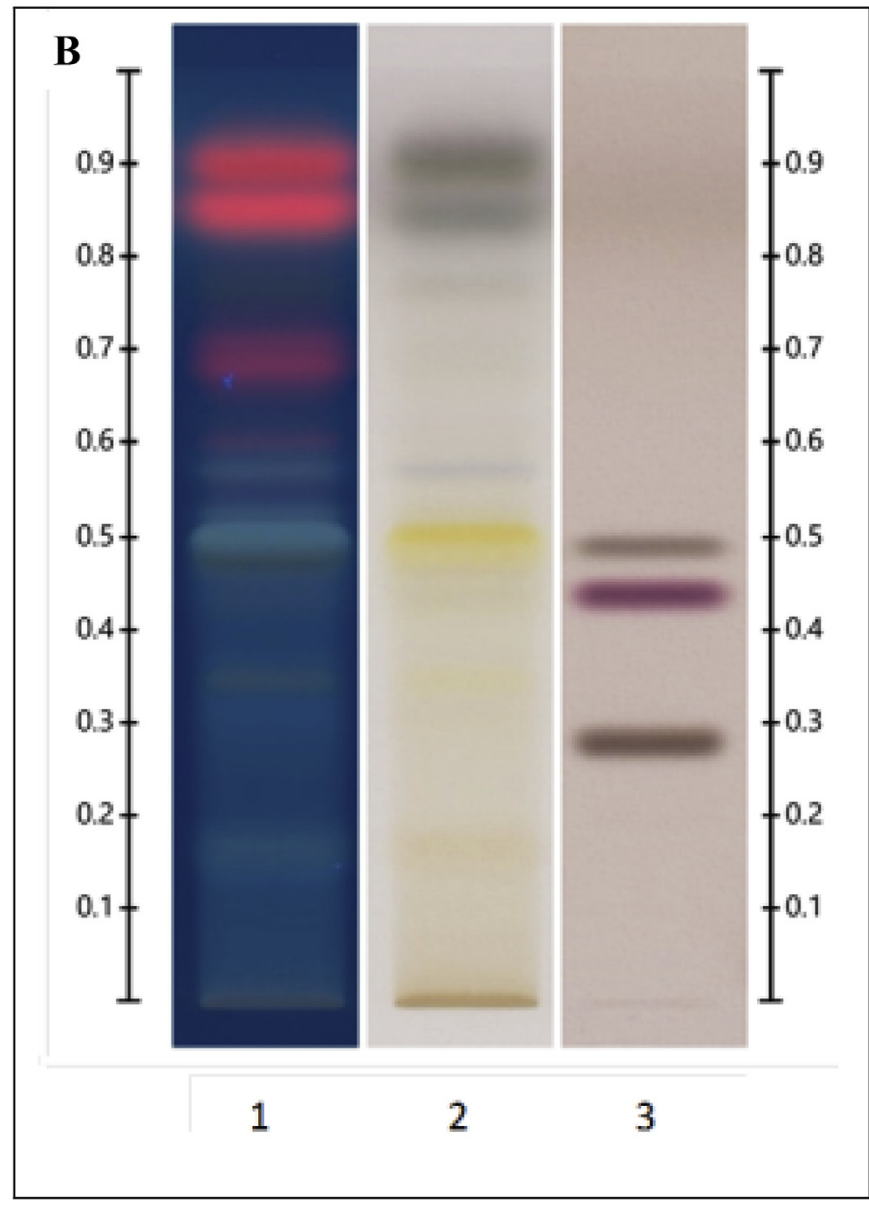

Fig. 1. bHPTLC profile of Clerodendrum cyrtophyllum leaves ethanolic extract (EE-CC, 1 and 2) and iridoids standard mix (from top to bottom: agnuside, geniposide, aucubin). Analysis was performed on silica gel 60 F254 HPTLC plates (Merck, Germany), using ethyl acetate - methanol - water (77:25:8, v/v/ v) as a solvent system; plates were sprayed with a solution of vanillin (1\%) and sulfuric acid ( $2 \%$ ) in $\mathrm{EtOH}$, heated for $5 \mathrm{~min}$ at $100{ }^{\circ} \mathrm{C}$ and visualized under UV $365 \mathrm{~nm}$ (1) and visible light (2 and 3).

\subsubsection{Effect of EE-CC on the production of TNF- $\alpha$ in LPS induced RAW} 264.7 cells

To further investigate the anti-inflammatory effect of EE-CC on LPSstimulated macrophages, the production of pro-inflammatory cytokines was evaluated by ELISA. As shown in Fig. 5, the cells treated with LPS alone showed a marked increase in TNF- $\alpha$ compared to untreated

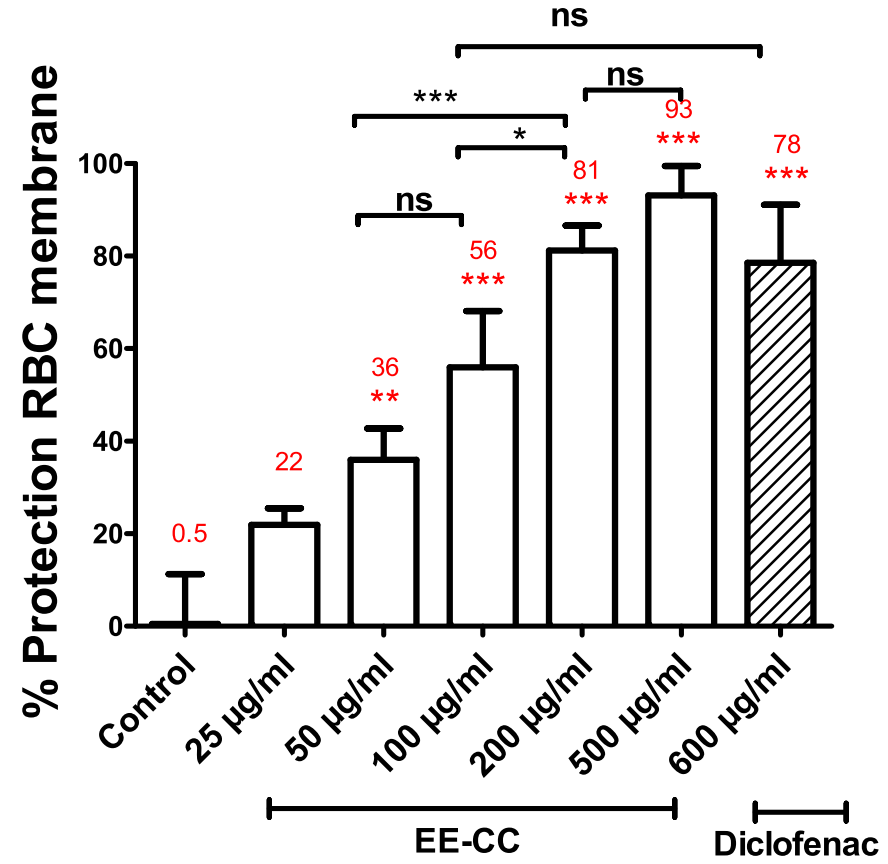

Fig. 3. Effect of the ethanol extract from C. cyrtophyllum leaves (EE-CC) on the hemolysis of red blood cells induced by heat. Each value is expressed as mean \pm SD $(\mathrm{n}=3)$. ${ }^{*} \mathrm{p}<0.05,{ }^{* *} \mathrm{p}<0.01,{ }^{* * *} \mathrm{p}<0.001$ compared to control.

Table 2

IC50 of EE-CC on hemolysis of red blood cells induced by heat

\begin{tabular}{lll}
\hline & EE-CC & Diclofenac \\
\hline IC50 $(\mu \mathrm{g} / \mathrm{ml})$ & 75 & 294 \\
Std. Error & 1.05 & 1.10 \\
$95 \%$ Confidence Intervals & $62.8-90.4$ & $213.4-404.6$ \\
$\mathrm{R}^{2}$ & 0.9919 & 0.9596 \\
Number of points analysed & 5 & 5 \\
\hline
\end{tabular}

control; this stimulation was significantly inhibited by treatment with EE-CC $(\mathrm{p}<0.01)$ at concentrations of 50,100 , and $200 \mu \mathrm{g} / \mathrm{ml}$. EE-CC $100 \mu \mathrm{g} / \mathrm{ml}$ was more potent than EE-CC $50 \mu \mathrm{g} / \mathrm{ml}$. No significant differences were observed between EE-CC 100 and $200 \mu \mathrm{g} / \mathrm{ml}$ in inhibition of TNF- $\alpha$ production. No differences were found in TNF- $\alpha$ production at the lower EE-CC concentrations of 12.5 and $25 \mu \mathrm{g} / \mathrm{ml}$ compare to control group (the cells treated with LPS alone)k. These data suggest that EE-CC has the ability to inhibit LPS-induced TNF- $\alpha$ production in mouse macrophages.

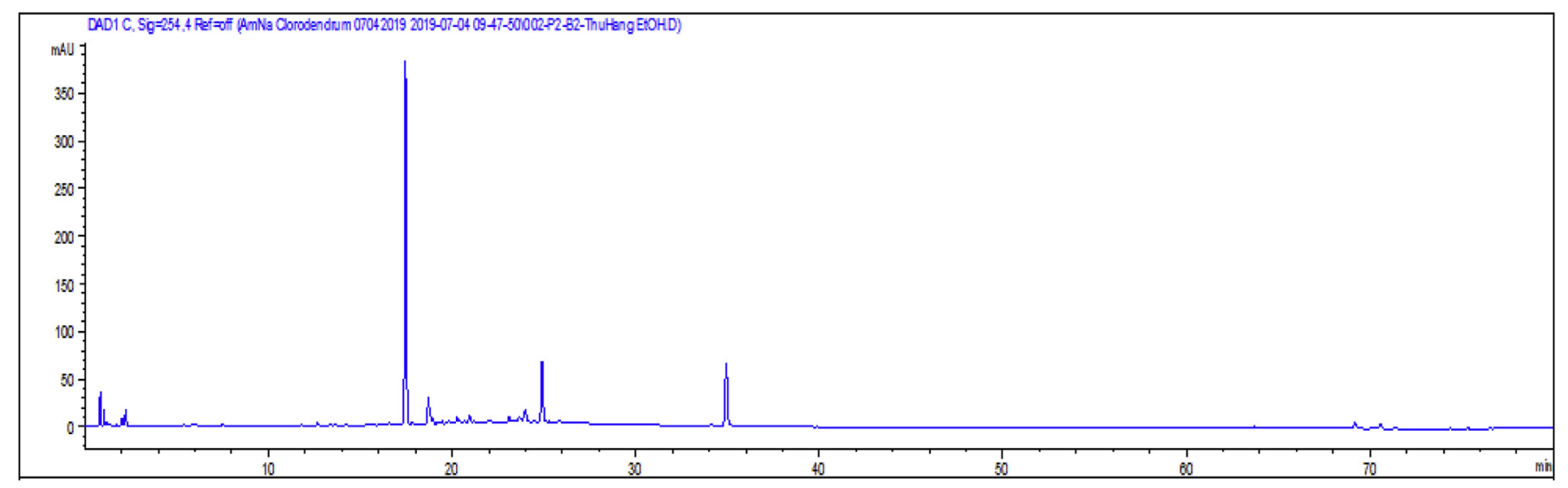

Fig. 2. Typical HPLC chromatogram of the C. cyrtophyllum ethanolic extract (EE-CC) recorded at $254 \mathrm{~nm}$. 


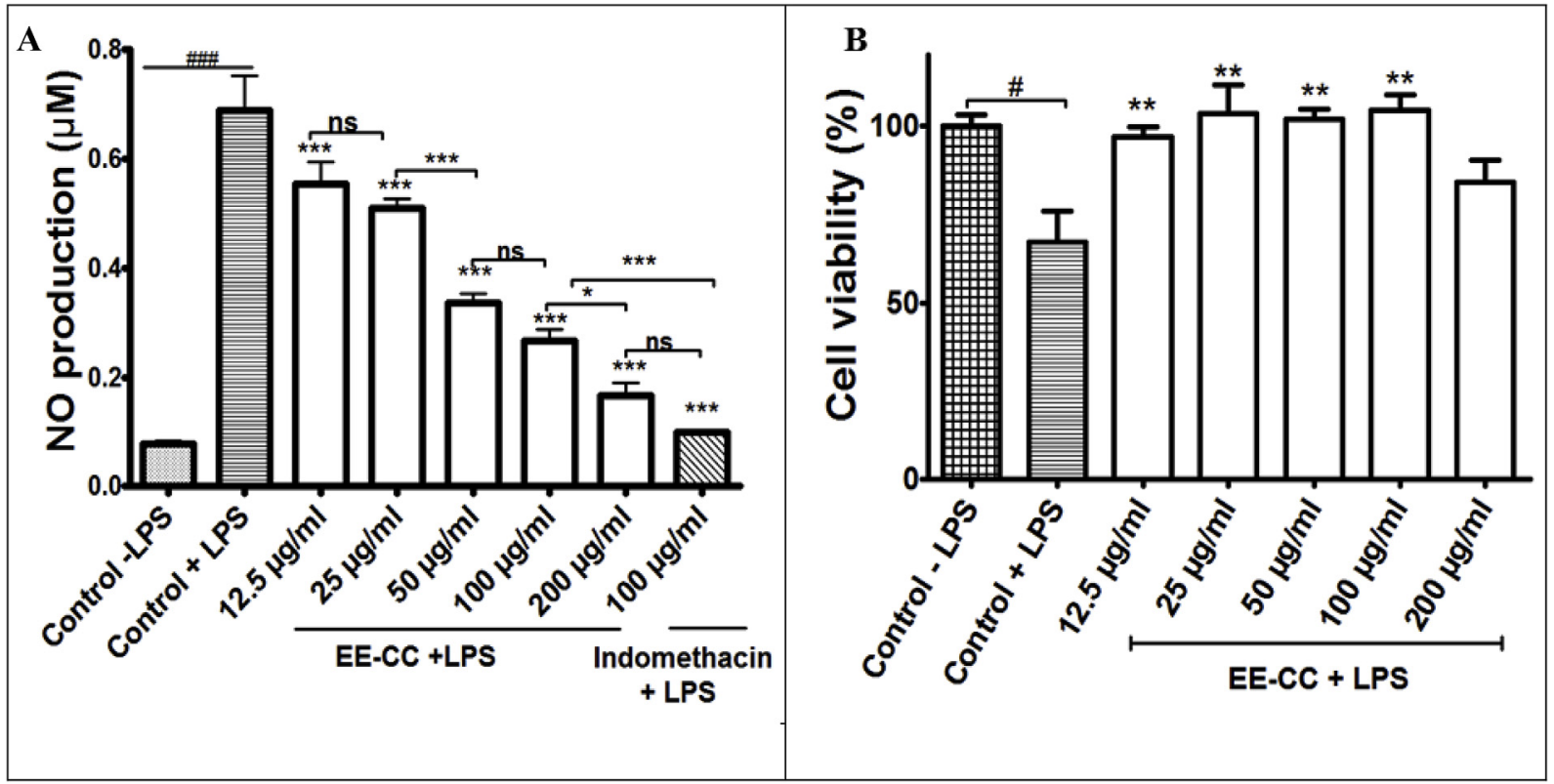

Fig. 4. A. Effect of ethanol extract from leaves of C. cyrtophyllum (EE-CC) on NO production.

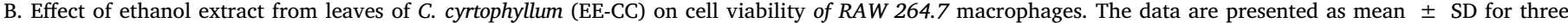
different experiments performed in triplicate, ${ }^{\# \#} \mathrm{p}<0.001$ compared to control-LPS, *p $<0.05$, **p $<0.01, * * * \mathrm{p}<0.001$ compared to control + LPS.

Table 3

IC50 of EE-CC on NO production.

\begin{tabular}{lll}
\hline & EE-CC & Indomethacin \\
\hline IC50 $(\mu \mathrm{g} / \mathrm{ml})$ & 48 & 47 \\
Std. Error & 1.1 & 1.2 \\
$95 \%$ Confidence intervals & $36.4-64.4$ & $28.3-79.2$ \\
$\mathrm{R}^{2}$ & 0.9787 & 0.9298 \\
Number of points analysed & 5 & 5
\end{tabular}

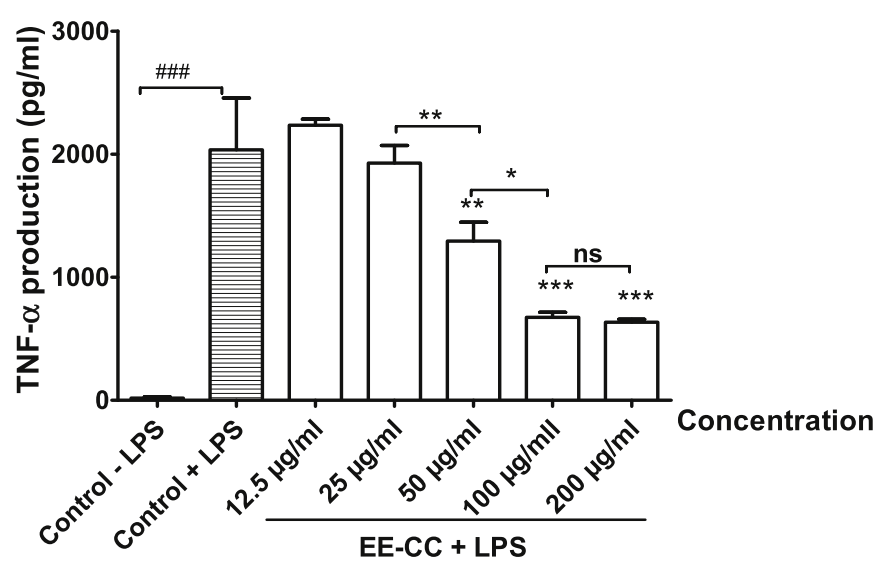

Fig. 5. Effects of EE-CC on TNF- $\alpha$ in LPS-induced RAW264.7 cells.

The data are presented as mean \pm SD for three different experiments performed in triplicate, ${ }^{*} \mathrm{p}<0.05,{ }^{* *} \mathrm{p}<0.01,{ }^{* * *} \mathrm{p}<0.001$ compared to control + LPS.

\subsection{In vivo experiment}

\subsubsection{The toxicity screening test}

3.4.1.1. Effect of EE-CC on survival rate of zebrafish larvae. To determine the optimal stage for treatment during the in vivo anti-inflammatory experiments, identical doses of EE-CC were exposed to $4 \mathrm{dpf}$ larvae. Our preliminary experiment revealed that the administration of EE-CC at

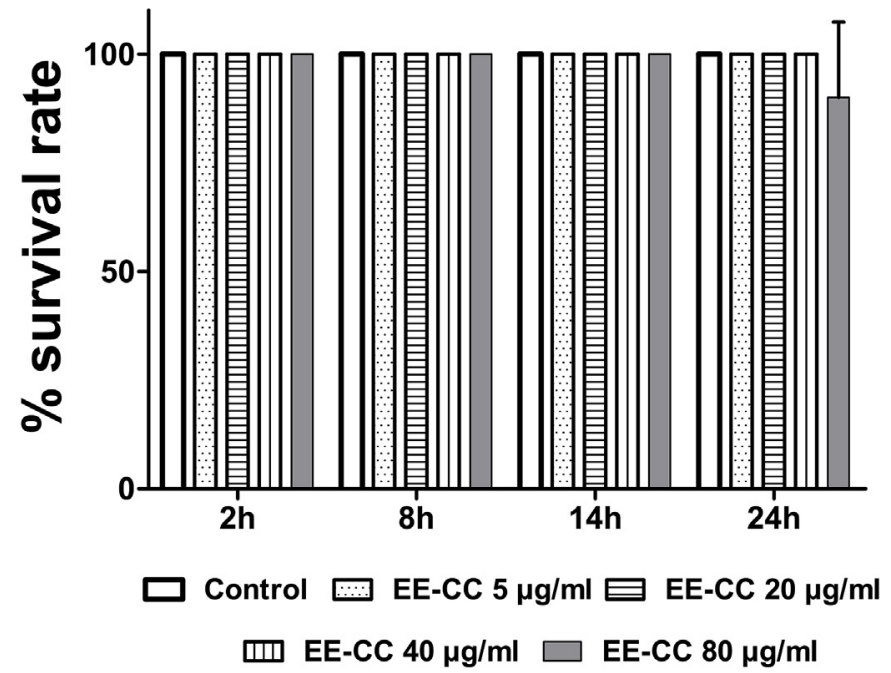

Fig. 6. aEffect of EE-CC on survival rate of zebrafish larvae.

$80 \mu \mathrm{g} / \mathrm{ml}$ induced changes in survival rate (\%) of animals at $24 \mathrm{~h}$ compared with control (Fig. 6A). Continuous EE-CC exposure at dose $80 \mu \mathrm{g} / \mathrm{ml}$ can induce higher mortality in zebrafish larvae. The time $24 \mathrm{~h}$ was therefore preferable. With the lower EE-CC doses $(5,20,40 \mu \mathrm{g} / \mathrm{ml})$ all the animals were physically active and no deaths were observed.

3.4.1.2. Effect of EE-CC on expression of the immune genes in normal larvae. In order to determine the optimal dose for treatment, we continued to evaluate the effects of EE-CC at doses 5, 20, 40 and $80 \mu \mathrm{g} / \mathrm{ml}$ on immune gene expression. Results are shown in Fig. 6B, C.

EE-CC at high dose $(80 \mu \mathrm{g} / \mathrm{ml})$ had immunotoxicity through upregulation in almost all immune genes tested when compared with the control group ( $p<0.05$ ). At a lower dose of $40 \mu \mathrm{g} / \mathrm{ml}$, EE-CC increased the expression of cox-2, c3a, pla2. However, no significant differences in immune gene expression were observed at the doses of 5 and $20 \mu \mathrm{g} / \mathrm{ml}$. These doses of 5, 20 and $40 \mu \mathrm{g} / \mathrm{ml}$ were considered no or less immunotoxic and were used for further experiments. 

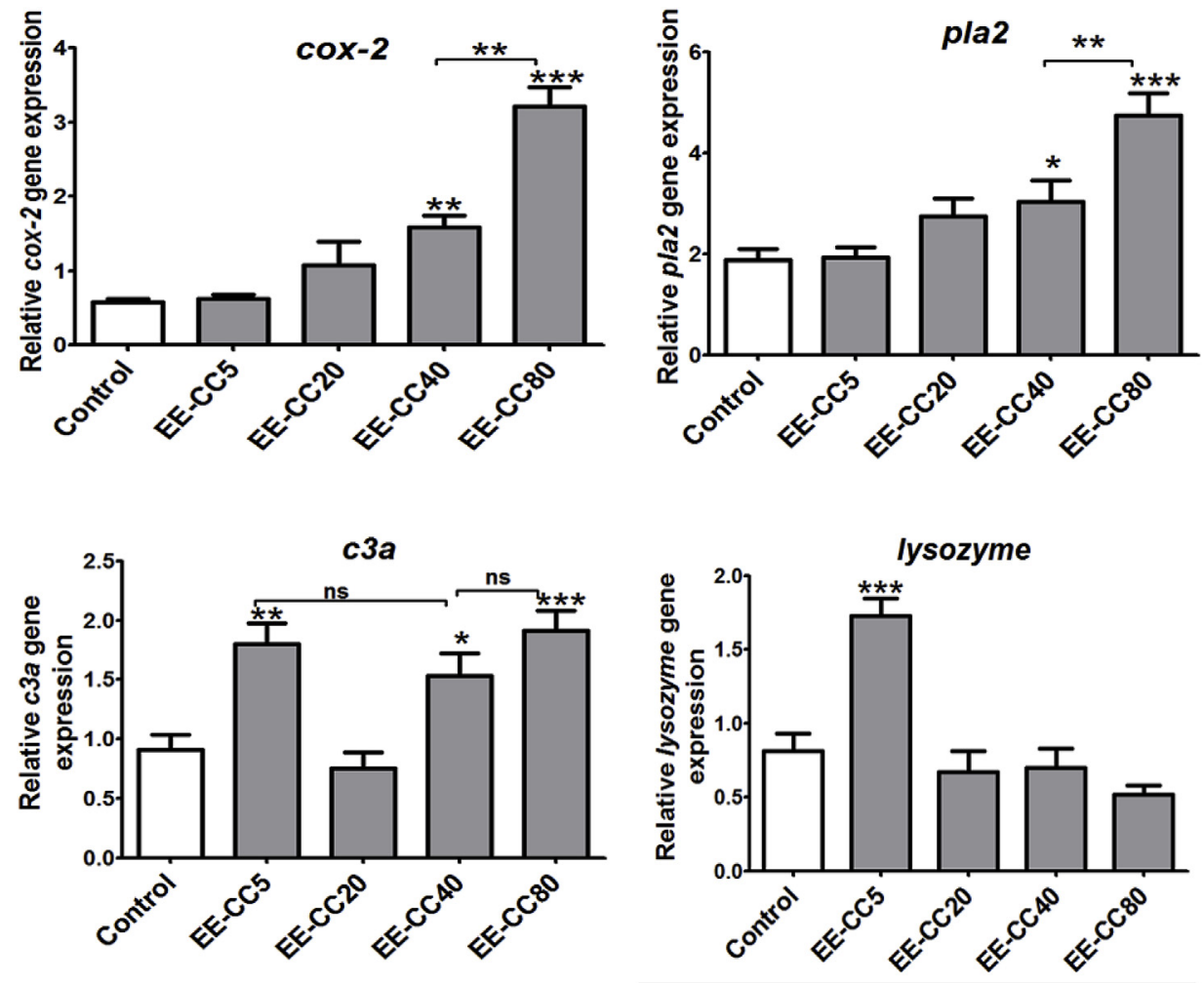

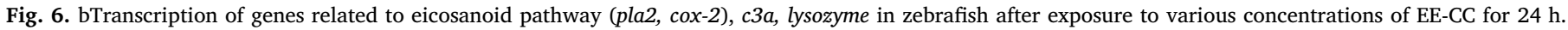

3.4.2. Effect of the ethanol extract from leaves of C. cyrtophyllum on the expression of immune genes in cut tail zebrafish larvae

3.4.2.1. The EE-CC inhibited the transcription of cox-2, c3a, pla2 in cut tail zebrafish larvae. To further investigate the mechanism of action, we determined the effects of EE-CC on the expression of two genes involved in the eicosanoid pathway (cox-2, pla2), and of the complement gene c3a and the lysozyme gene. As shown in Fig. 7, cut tail increased the expression of cox-2, c3a, pla2 genes significantly when compared with the control group (no cut tail). Treatment with dexamethasone reduced the inflammatory reaction, as revealed by down-regulating expressions of cox-2 and pla2 ( $\mathrm{p}<0.05$ ). Similarly to dexamethasone, EE-CC at the dose of $20 \mu \mathrm{g} / \mathrm{ml}$ and $5 \mu \mathrm{g} / \mathrm{ml}$ prominently suppressed the cut tailinduced mRNA levels of cox-2, pla2 and c3a. In general, these results are consistent with the anti-inflammatory activity of the extract. At the highest dose of $40 \mu \mathrm{g} / \mathrm{ml}$, EE-CC only inhibited expression of $c 3 a$ gene (Fig. 7 C). No differences were observed on lysozyme expression in all treatment groups when compared with the cut tail and no treatment group (Fig. 7D).

3.4.2.2. EE-CC inhibited the transcription of tail cut-induced proinflammatory cytokines in zebrafish larvae. In response to cut tail, macrophages in zebrafish larvae could release pro-inflammatory cytokines, such as TNF- $\alpha$, IL-1, IL- 6 and IL-8. The aberrant release of these cytokines contributes to the pathogenesis of many chronic inflammatory diseases such as rheumatoid arthritis (RA) and inflammatory bowel diseases. We thus examined whether the expression of these genes is increased by the tail cut, and subsequently whether EE-CC inhibits tail cut-induced expression of tnf- $\alpha$, il-1(il1fma), and il-8 (cxcl8b.1) in the concentration range of 5, 20 and $40 \mu \mathrm{g} / \mathrm{ml}$. Real-time RT-PCR analysis revealed that tail cut activated inflammation by increasing the expression of il-1(il1fma), il8 (cxcl8b.1) and thf- $\alpha$ compared to the control group (no cut tail). Dexamethasone $5 \mu \mathrm{g} / \mathrm{ml}$ exerted its anti-inflammatory activity by reverting the increase in expression of il-1(il1 fma) and il-8 (cxcl8b.1) genes ( $\mathrm{p}<0.05$ ), but not of tnf- $\alpha$. Exposing the zebrafish larvae to EE-
CC resulted in a similar decrease in the mRNA levels of $i l-8$ (cxcl8b.1) and il-1(il1fma), and also in tnf- $\alpha$ at $20 \mu \mathrm{g} / \mathrm{ml}$ (p $<0.05$ ). EE-CC down-regulated il-1(illfma) expression even at both $5 \mu \mathrm{g} / \mathrm{ml}$ and $40 \mu \mathrm{g} /$ $\mathrm{ml}$ (Fig. 8A, B, C). These results suggest that EE-CC in the concentration range of $5-40 \mu \mathrm{g} / \mathrm{ml}$ inhibits the increase in expression of proinflammatory cytokines that are induced by cutting the tail in zebrafish larvae.

3.4.2.3. EE-CC reduced cut tail-induced expression of $n f-k b$. NF- $\mathrm{kB}$ is a major transcription factor that modulates the expression of many proinflammatory cytokines (tnf- $\alpha$, il-1 $\beta$, and il-6). As shown in Fig. $8 \mathrm{D}$, the tail cut caused a significant increase in $n f-k b$ expression, which was inhibited by EE-CC at $20 \mu \mathrm{g} / \mathrm{ml}$ ( $\mathrm{p}<0.05$ ), suggesting that its ability to inhibit $n f-k b$ expression may underlie its anti-inflammatory effects.

3.4.2.4. EE-CC up-regulated expression of anti-inflammatory cytokine il10. Interleukin 10 (IL-10) is a cytokine with potent anti-inflammatory properties that plays a central role in limiting the host's immune response to pathogens, thereby preventing damage to the host and maintaining normal tissue homeostasis (Iyer and Cheng, 2012). As shown in Fig. 9, EE-CC at $40 \mu \mathrm{g} / \mathrm{ml}$ up-regulated il-10 expression $(\mathrm{p}<0.05)$.

3.4.2.5. Effect of the ethanol extract from leaves of C. cyrtophyllum Turcz on expression of the vcam, inos, mpo genes. Cutting the tail of $4 \mathrm{dpf}$ zebrafish larvae decreased the expression of inos and increased the expression of mpo after $24 \mathrm{~h}$, while the levels of $v$ cam were not affected. No differences were observed on inos, vcam expression in all treatment groups when compared with the cut tail group (Fig. 10).

\section{Discussion}

\subsection{Total phenolic and flavonoid contents}

Phenolic compounds play an important role in a variety of 

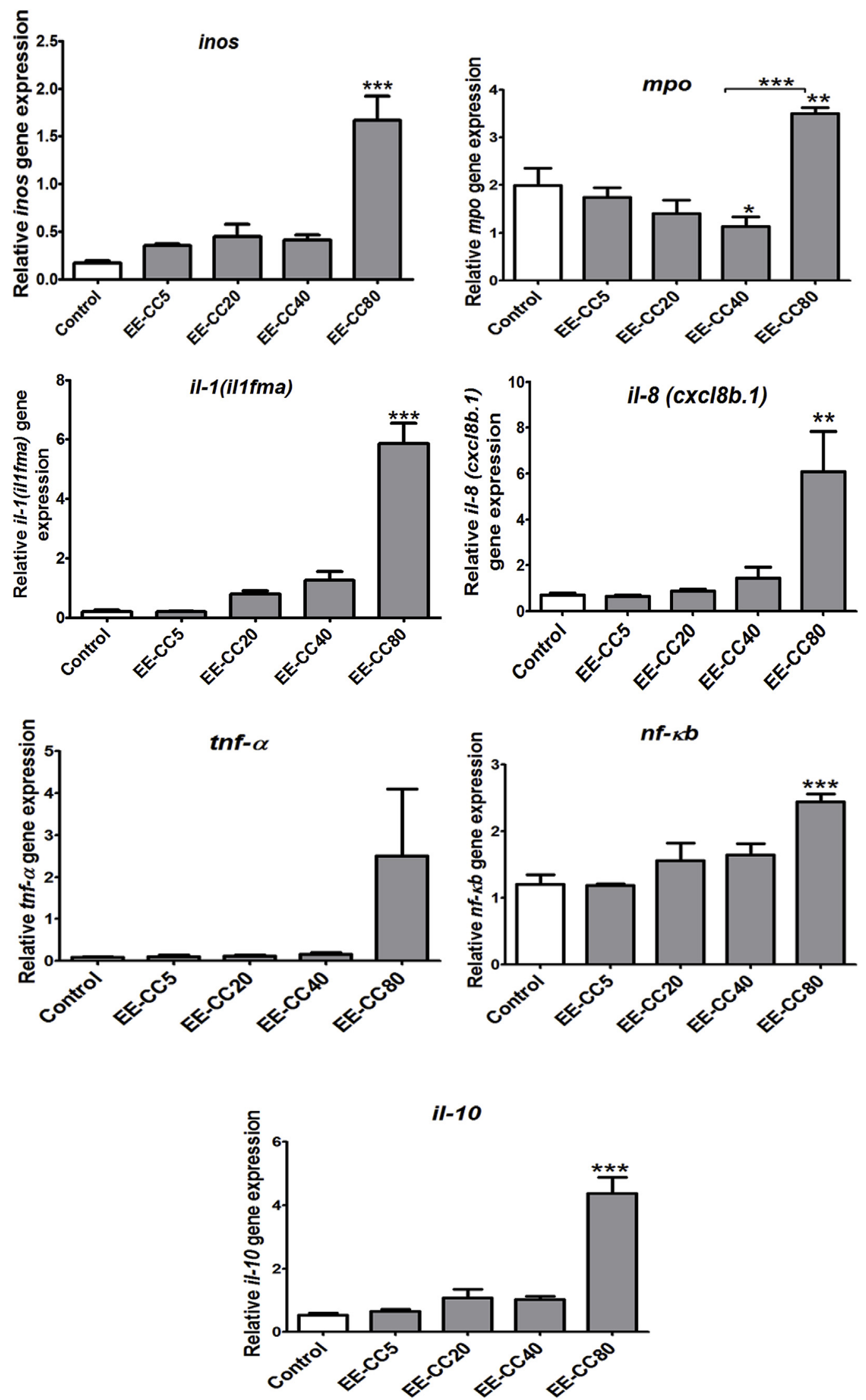

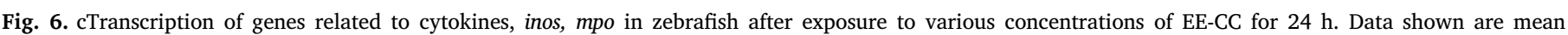
values \pm SEM of 3 independent wells, 20 larvae/well, *p $<0.05 ; * * p<0.01 ; * * \mathrm{p}<0.001$ compared to control group. 

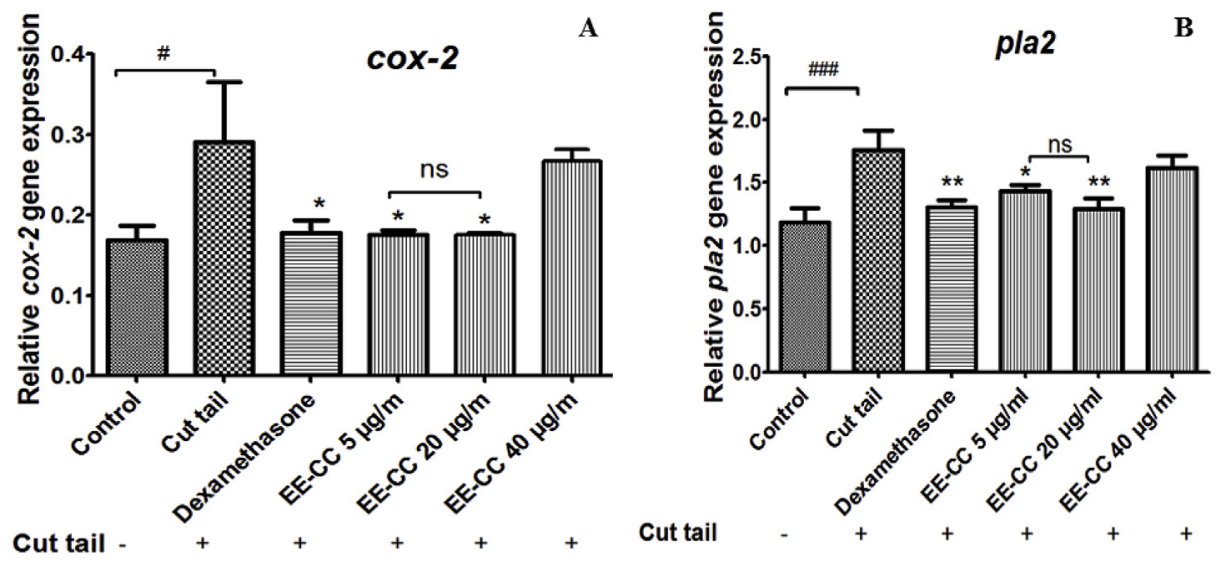

Fig. 7. Effect of ethanol extract from leaves of $C$. cyrtophyllum (EE-CC) on the expression of genes in eicosanoid pathway (pla2, cox-2) and c3a, lysozyme.

Data shown are mean values \pm SEM of 3 independent wells, 20 larvae/well. ${ }^{*} \mathrm{p}<0.05$; \#\# $\mathrm{p}<0.01 ;{ }^{\# \# \#} \mathrm{p}<0.001$ compared to control group; ${ }^{*} \mathrm{p}<0.05 ; * * \mathrm{p}<0.01 ; * * * \mathrm{p}<0.001$ compared to cut tail group.

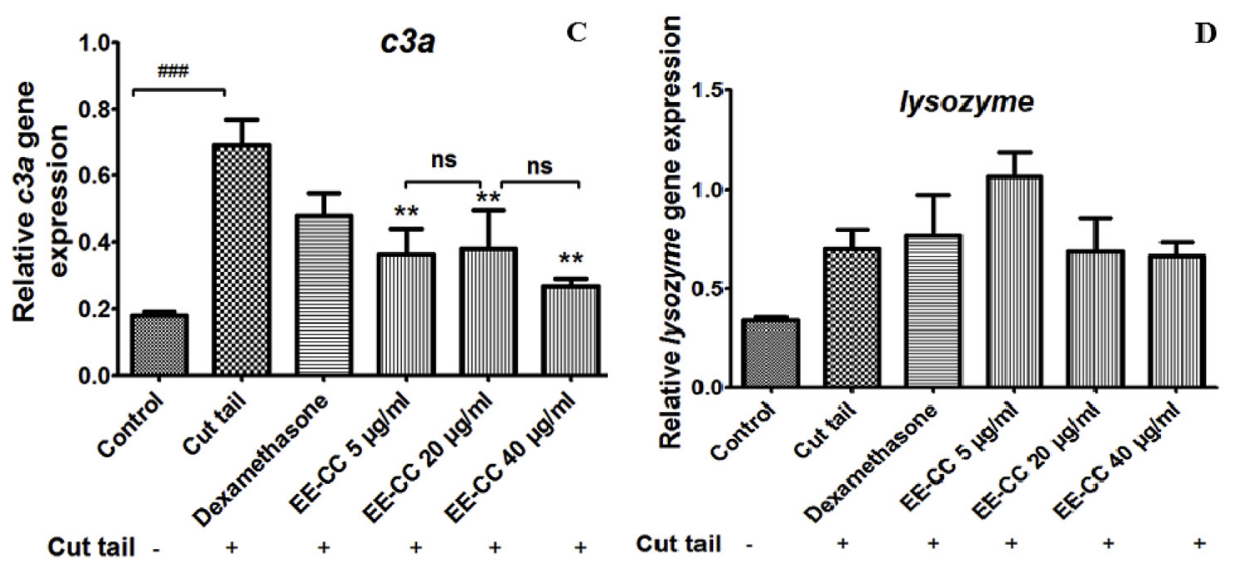

medicinal applications. The ethanolic extract of the $C$. cyrtophyllum leaves analysed in this study presented a concentration of total phenolic compounds of $23.3 \pm 1.5 \mathrm{GAE} \mathrm{mg} / \mathrm{g}$ expressed in dry weight of leave material. This concentration is higher than the total phenolic content reported by Li et al. (2008) (11.9 $\pm 0.3 \mathrm{GAE} \mathrm{mg/g} \mathrm{DW)} \mathrm{for} \mathrm{methanolic}$ extract of $C$. cyrtophyllum obtained by maceration at $40{ }^{\circ} \mathrm{C}$ and by Zhou et al. (2013) (16.8 $\pm 0.2 \mathrm{GAE} \mathrm{mg/g} \mathrm{DW)} \mathrm{for} \mathrm{an} \mathrm{ethanolic} \mathrm{ultrasonic-}$ assisted extraction at $63.3{ }^{\circ} \mathrm{C}$ of $\mathrm{C}$. cyrtophyllum leaves. Flavonoids content was evaluated at $2.97 \pm 0.01 \mathrm{QE} \mathrm{mg} / \mathrm{g}$ expressed in dry weight of leaves. This is higher than the flavonoids content reported by Liu et al. (2011) (0.50 $\pm 0.47 \mathrm{QE} \mathrm{mg/g} \mathrm{DW)} \mathrm{for} \mathrm{methanolic} \mathrm{extract} \mathrm{of}$ C. cyrtophyllum.

4.1.1. Influence of the ethanol extract from C. cyrtophyllum Turcz on inhibition of hemolysis

The erythrocyte membrane is similar to the lysosomal membrane (Kumar et al., 2011). The stabilization of the lysosomal membrane prevents the release of lysosomal constituents and has an important role in limiting the inflammatory response (Parvin et al., 2015). In this study, the ethanol extract from C. cyrtophyllum leaves exhibited erythrocyte membrane stabilization by inhibiting heat-induced hemolysis. This indicates that the ethanol extract of C. cyrtophyllum leaves possesses biological membrane stabilization properties, preventing or delaying stress-induced destruction of the plasma membrane.

\subsection{Influence of the ethanol extract from C. cyrtophyllum on NO production}

Macrophages are an important component in the immune defense mechanism. During the progress of inflammation, macrophages actively participate in the inflammatory responses by releasing proinflammatory cytokines and mediators such as free radicals and NO as well as cytokines (Bak et al., 2013). An overproduction of NO has been implicated in the pathogenesis of septic shock, inflammation, and carcinogenesis. Thus, agents that decrease NO production in macrophages may have a potential therapeutic effect on the treatment of inflammatory and infectious diseases. Our results demonstrate that the ethanol extract from C. cyrtophyllum leaves strongly inhibited LPS-induced NO production without notable cytotoxicity in RAW264.7 macrophages. This result is in line with a previously paper by Liu et al. (2011) in which a C. cyrtophyllum methanolic extract significantly inhibited NO production through down-regulation of iNOS expression in LPS-stimulated RAW264.7 cells. In contrast to the induction of iNOS expression in LPS-stimulated RAW264.7 macrophages, the zebrafish larvae model showed that tail cut down-regulated the inos gene expression, while EE-CC had no effect on inos expression. The difference most probably results from differences in complexity between cell cultures and whole organisms. In vitro models reflect pathway and gene expression modulations resulting from direct action of compounds on the cells, while more complex interactions between different systems take place in in vivo systems. This is a disadvantage of the in vitro tests and it remains one of the bottlenecks in drug development (Otava et al., 2015).

Depending on the concentration of NO released into the tissue microenvironment and the type and stage of inflammation, NO seems to exhibit either anti- or pro-inflammatory effects (Hyun et al., 2004). It has been well documented that excessive production of NO via iNOS is involved in the pathogenesis of several inflammatory disorders. Studies with iNOS-deficient mice however indicate that the production of NO might be needed as a protective factor in various models of acute or chronic inflammation (Kenyon et al., 2002). In a model of contact hypersensitivity, an inhibition of NO synthesis caused the release of inflammatory mediators such as histamine and platelet-activating factor (PAF) from mast cells. Impairment of NO production resulted in a 


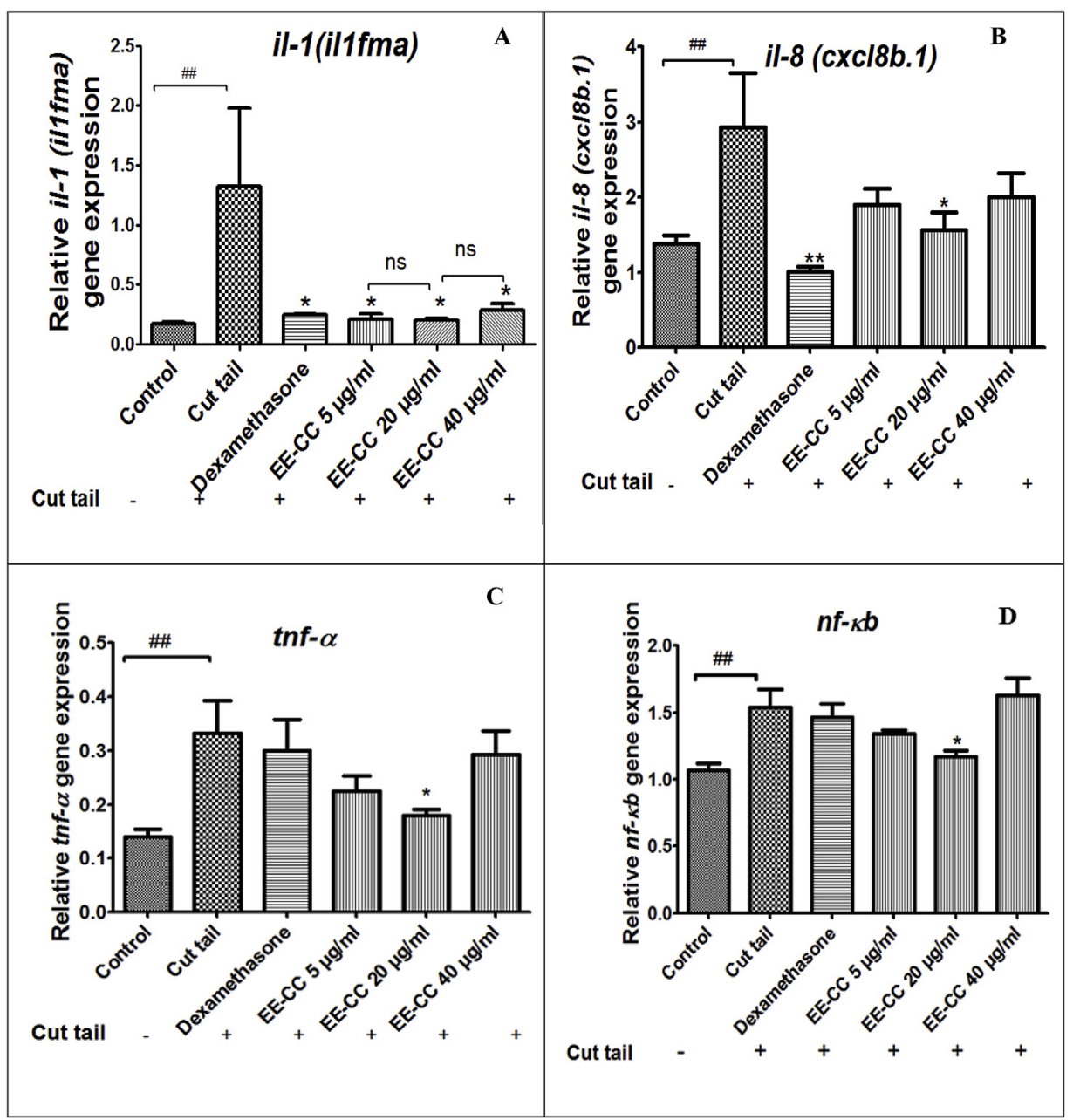

Fig. 8. Relative expression of genes involved in immune responses (il-1(il1fma),il-8 (cxcl8b.1), tnf- $\alpha, n f-k b$ ) of zebrafish larvae after tail cut and treatment with the ethanol extract (EE-CC) from C. cyrtophyllum. Data shown are mean values \pm SEM of 3 independent wells, 20 larvae/well. \#\#p < 0.01; \#\#\#p < 0.001 compared to control group; *p $<0.05 ; * * \mathrm{p}<0.01 ; * * \mathrm{p}<0.001$ compared to cut tail group.

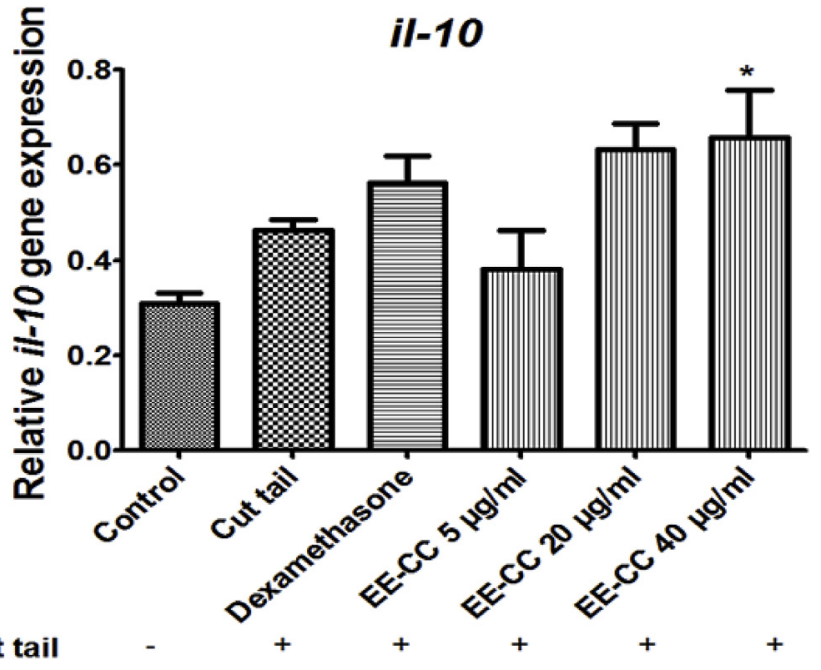

Fig. 9. Effects of EE-CC on the expression of the anti-inflammatory gene il-10 in inflammation- induced zebrafish model. Data shown are mean values \pm SEM of 3 independent wells, 20 larvae/well. *p $<0.05 ; * * \mathrm{p}<0.01$; $* * * \mathrm{p}<0.001$ compared to tail cut group. pattern of leukocyte adhesion and emigration that is characteristic of acute inflammation (Kubes et al., 1991). Further studies are raising the possibility that the use of NO donors may be a reasonable therapeutic approach to reducing mast cell-dependent inflammation. Anti-inflammatory drugs that have been modified to include a NO-releasing moiety have been recently developed and have shown enhanced antiinflammatory activities together with reduced side-effects (Hyun et al., 2004). In line with these observations, in the tail cut zebrafish model, our results show that cutting the tail significantly inhibited inos expression, suggesting that inflammation is associated with decreased NO production. However, EE-CC didn't protect larvae from NO deficiency.

\subsection{Influence of the ethanol extract from C. cyrtophyllum on vcam and} mpo expression in tail cut-induced inflammation in zebrafish larvae

VCAM was identified as a cytokine-inducible adhesion molecule present on endothelial cells and mediating their binding to leukocytes. IL-1 and TNF- $\alpha$ signaling regulate the response of cells through upregulating VCAM expression, with maximal activity reached after 6-12 h (Imhof and Dunon, 1995). In our study, no significant changes in $v$ cam expression were observed between experimental groups, suggesting that the expression of $v c a m$ was unaffected by those treatments or that the timing $(24 \mathrm{~h})$ was not correct.

Neutrophils are the first leukocyte to migrate to the site of the infection. There, they phagocyte pathogens and subsequently kill the invading microbes (Mayadas et al., 2014). MPO, the major protein in 


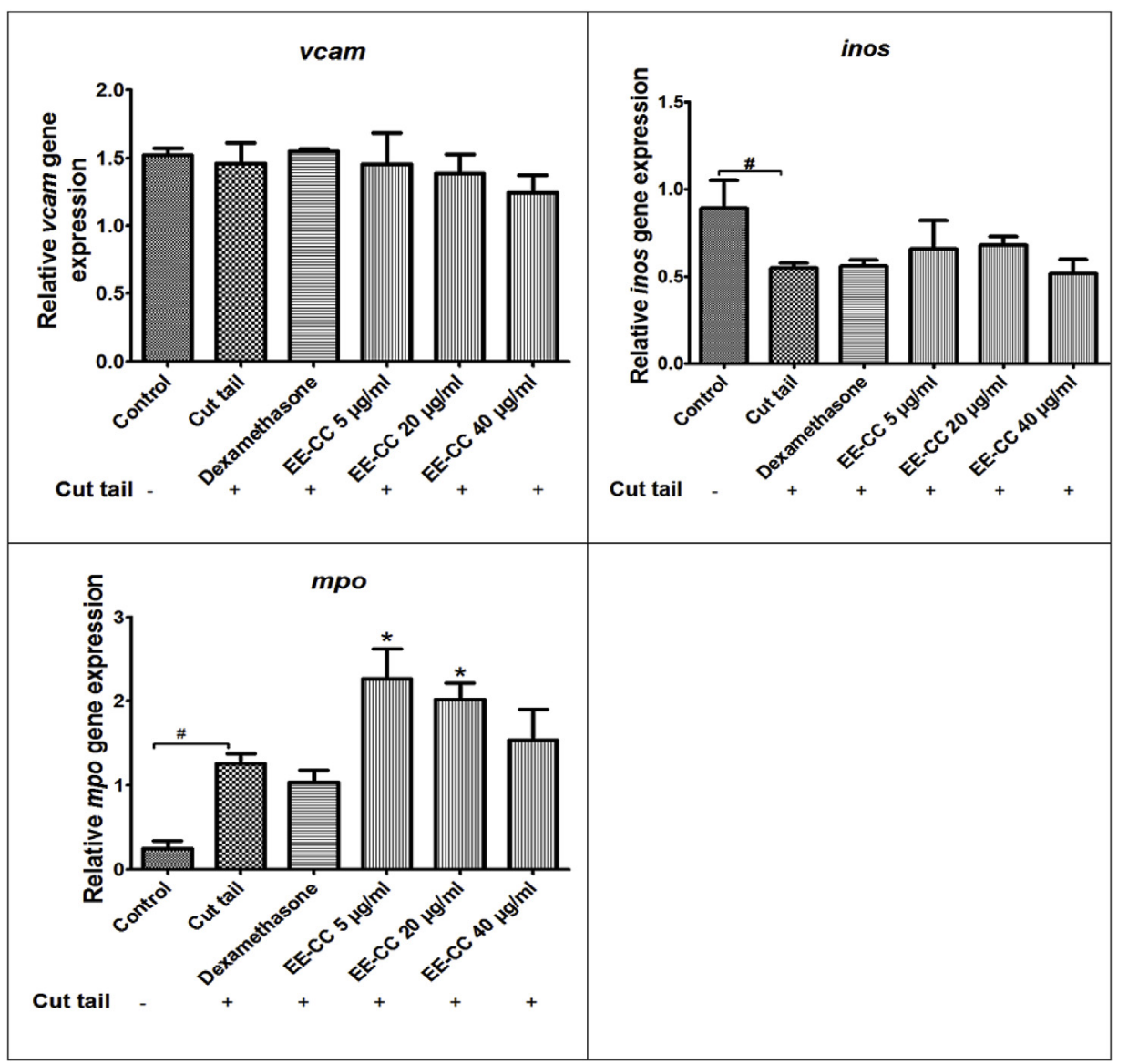

Fig. 10. Effect of the ethanol extract (EE-CC) from leaves of $C$. cyrtophyllum Turcz on the expression of the vcam, inos, mpo genes.

Data shown are mean values \pm SEM of 3 independent wells, 20 larvae/well. ${ }^{\#} \mathrm{p}<0.05$ compared to control group; ${ }^{*} \mathrm{p}<0.05$ compared to cut tail group.

neutrophil granules, is one of the key players in the neutrophil functions described above (Odobasic et al., 2016). Based on the principle of generating a mechanical injury to attract leukocytes to damaged zones, tail transection results in a robust recruitment of leukocytes to the zone of injury as illustrated by in situ myeloperoxidase (MPO) staining (Cordero-maldonado et al., 2013). Unexpectedly, exposure to EE-CC led to an even higher mpo expression; possibly due to tail cutting, EE-CC could be directly absorbed by contact with the zone of injury. The body recognizes EE-CC as "foreign" and activates phagocyting neutrophils to tail transection position. Such an exposure would lead to an even greater migratory response of neutrophils to the injury site and higher expression of mpo expression. Beside, the compounds contained in EECC also can be directly immunogenic. These compounds can penetrate intact larval skin or absorpt through digestive tract (intestinal absorption) and express immunogenic activity. In larvae with intact skin, only the high dose of EE-CC at $80 \mu \mathrm{g} / \mathrm{ml}$ expressed immunogenic activity, increased mpo expression (Fig. 6C). At lower doses (5, 20, $40 \mu \mathrm{g} / \mathrm{ml}$ ), EE-CC did not show any immunogenic activity in intact larvae. However, in cut tail larvae, EE-CC can absorpt through open injury. This increased extent of absorption of EE-CC. So at low doses (5, 20, $40 \mu \mathrm{g}$ / $\mathrm{ml}$ ), EE-CC can express immunogenic activity and may induce expression of mpo.

\subsection{Influence of the ethanol extract from C. cyrtophyllum on enzyme expression in eicosanoid pathway}

In mammalian cells, eicosanoid biosynthesis is usually initiated by the activation of phospholipase A2 and the release of arachidonic acid (AA) from membrane phospholipids. The AA is subsequently transformed by cyclooxygenase (COX) and lipoxygenase (LO) pathways to prostaglandins, thromboxane and leukotrienes, collectively termed "eicosanoids". Both COX-2 and PLA2 are important enzymes in the eicosanoid pathway. Inhibiting the expression of these 2 enzymes resulted in decreased production of mediators such as prostaglandins, arachidonic acid, thromboxane and leukotrienes which is beneficial for treating pain and inflammation. The inhibition of this pathway is the major target for conventional drugs to treat pain and inflammation in clinical test (Khanapure et al., 2007). EE-CC at the dose of 5 and $20 \mu \mathrm{g} /$ $\mathrm{ml}$ prominently suppressed the tail cut -induced mRNA levels of cox-2 and pla2. These results suggest that EE-CC could be a promising option for the prevention and treatment of inflammation through inhibition of inflammatory mediators formation.

\subsection{Influence of the ethanol extract from C. cyrtophyllum on the expression} of cytokines

Proinflammatory cytokines are produced predominantly by activated macrophages and are involved in the up-regulation of inflammatory reactions. There is abundant evidence that certain pro-inflammatory cytokines such as IL-1 $\beta$, IL-2, TNF- $\alpha$, IL-6, IL-8, IFN- $\gamma$ are involved in the process of pathological inflammation. Because of this, the cytokine system constitutes a very interesting target for the development of clinically relevant anti-inflammatory drugs. In this study, EECC down-regulated the expression of tnf- $\alpha$, il-8 (cxcl8b.1) at $20 \mu \mathrm{g} / \mathrm{ml}$ and il-1(il1fma) at 5, 20 and $40 \mu \mathrm{g} / \mathrm{ml}$.

The regulation of inflammatory gene transcription is controlled by specific signaling pathways and transcription factors, such as NF- $\kappa$ B and AP-1. In response to stimulation, NF- $\kappa$ B is liberated from a complex with $\mathrm{I}-\mathrm{\kappa B}$ and induces transcription of inflammatory genes such as iNOS, COX-2, TNF- $\alpha$, IL-1, and IL- 6 chemokines and adhesion 
molecules that cause acute inflammation and a systemic inflammatory response syndrome (Liu and Malik, 2006). Therefore, blocking the NF$\kappa \mathrm{B}$ transcriptional activity can suppress the expression of iNOS, COX-2, and proinflammatory cytokines. In this study, the ethanol extract from C. cyrtophyllum inhibited the expression of $n f-k b$ at the dose of $20 \mu \mathrm{g} / \mathrm{ml}$. That explains the decrease of TNF- $\alpha$ and NO production in LPS induced RAW264.7 cells.

4.6. Influence of the ethanol extract from C. cyrtophyllum on the expression of anti-inflammatory cytokine- il-10

The anti-inflammatory cytokines are a series of immunoregulatory molecules that control the pro-inflammatory cytokine response. Major anti-inflammatory cytokines include IL-1 receptor antagonist, IL-4, IL10, IL-11, and IL-13. Among all the anti-inflammatory cytokines, IL-10 is a cytokine with potent anti-inflammatory properties, repressing the expression of inflammatory cytokines such as TNF- $\alpha$, IL- 6 and IL- 1 by activated macrophages. In addition, IL-10 can up-regulate endogenous anti-cytokines and down-regulate pro-inflammatory cytokine receptors. Thus, it can counter-regulate the production and function of pro-inflammatory cytokines at multiple levels (Zhang and An, 2007). In our study, EE-CC upregulated il-10 expression. That promises in the treatment of diseases related to an inflammatory process.

\subsection{The relation between dose and response}

At low dose $5 \mu \mathrm{g} / \mathrm{ml}$, EE-CC induced an anti-inflammatory effect through the down regulation of cox-2, pla2, c3a, il-1(il1 fma). This effect increased with increasing of doses; at the dose of $20 \mu \mathrm{g} / \mathrm{ml}$, EE-CC generally down-regulated almost tested genes. However, at a dose of $40 \mu \mathrm{g} / \mathrm{ml}$, EE-CC sometimes showed lower or no effects. A likely explanation for the lack of a dose-response curve for EE-CC might be related to immunotoxicity. At a dose of $40 \mu \mathrm{g} / \mathrm{ml}$, EE-CC alone expressed immunotoxicity through up-regulated expression of cox-2, pla2, c3a. This probably explains a decreasing anti-inflammatory effect compared to the dose of $20 \mu \mathrm{g} / \mathrm{ml}$.

\subsection{The relation between the chemical constituent(s) of the plant and anti- inflammatory effects}

The exact mechanism for the anti-inflammatory effects induced by C. cyrtophyllum extract and the chemical constituent(s) responsible for this effect are not yet known. The present study indicates a high level of phenols and flavonoids in EE-CC.

Phenolic compounds play an important role in a large variety of medicinal applications. The production of ROS, such as lipid peroxides and superoxides, is reported to be accountable for cell membrane destabilization. Phenolic compounds are reported to act as antioxidant agents through inhibition of ROS formation and/or upregulation of antioxidant defenses (Kumar and Pandey, 2013). Thus, it is not unreasonable to postulate that phenolic compounds in $C$.cyrtophyllum Turcz leaf extracts could be responsible for the membrane-stabilizing effect observed in this study.

Flavonoids are one of the major groups present in Clerodendrum genus possessing promising biological activities (Shrivastava and Patel, 2007). "Several studies have shown that flavonoids exhibit analgesic and anti-inflammatory effects as a result of their membrane- stabilizing ability in various experimental models "(Ranasinghe et al., 2012). It has been reported that flavonoids can inhibit expression of iNOS, COX, LOX, which are responsible for the production of a great number of mediators of the inflammatory process such as NO, prostaglandin, leukotriene as well as adhesion molecules (Kumar and Pandey, 2013). It has been found that several flavonoids can decrease the expression of different pro-inflammatory cytokines/chemokines, among which TNF$\alpha$, IL-1ß, IL-6, IL-8, MCP-1, in many cell types (Santangelo et al., 2007). These studies strongly support the idea that flavonoids can modulate the immune response and have potent anti-inflammatory activity.

Other phytochemicals could however be important for the investigated activities. In previous studies, the glycosidated coumaramide clerodendiod B, isolated from C. cyrtophyllum, has been reported to exhibit anti-inflammatory effects through the inhibition of the NF- $\mathrm{\kappa B}$ pathway in NF-kB reporter Luciferase Assay (Wang et al., 2012). Iridoid glycosides described in other Clerodendron species (Erukainure et al., 2014; Kanchanapoom et al., 2001, 2005) could also account for antiinflammatory activities and their presence should be investigated in $C$. cyrtophyllum.

\section{Conclusions}

In conclusion, the ethanol extract from C. cyrtophyllum Turcz displayed significant in vitro anti-inflammatory activity through lysosome membrane stabilization and decrease of proinflammatory mediator production (TNF- $\alpha$ and NO) in LPS-induced macrophages. Furthermore, in vivo results in zebrafish confirm that the ethanol extract from $C$. cyrtophyllum inhibits the inflammation via the downregulation of inflammatory genes expression (cox-2, pla2, c3a, il-1(il1fma), il-8 (cxcl8b.1), thf- $\alpha, n f-k b)$ and the upregulation of the anti-inflammatory gene il-10. These in vivo results contribute to understanding the molecular mechanisms of this action. Taken together, these findings provide a pharmacological validation to the traditional use of $C$. cyrtophyllum Turcz leaves in the treatment of inflammatory disorders.

\section{Author contributions}

$\mathrm{NH}, \mathrm{PK}, \mathrm{AN}, \mathrm{NM}, \mathrm{VC}$ contributed to the conception and design of the study. NH and VC performed the statistical analyses. PD, MM, DH, PK provided funding sources and edited the paper. All authors read and approved the submitted version.

\section{Declaration of competing interest}

The authors declare no conflicts of interest.

\section{Acknowledgements}

This research was funded by ARES (Académie de Recherche et d'Enseignement Supérieur) and the Ministry of Cooperation (DGD (Direction Générale de la Coopération au Développement)) in Belgium.

\section{References}

Bak, M., Truong, V.L., Kang, H., Jun, M., Jeong, W., 2013. Anti-inflammatory effect of procyanidins from wild grape (Vitis amurensis) seeds in LPS-induced RAW 264.7 cells. Oxid. Med. Cell. Longev 2013.

Begum, N., Srisailam, K., V, U.M.R., 2016. Investigation of invitro anti inflammatory and COX-2 inhibitory activity of root extracts of Berberis aristata. Int. J. Pharm. Biol. Sci. 6, 84-88.

Bio-Rad, 2006. Real-Time qPCR Data Analysis Data Analysis. Real-Time PCR Appl. Guid,

Chen, K., Wang, C., Fan, Y., Xie, Y., Yin, Z., Xu, Z., Zhang, H., Cao, J., Han, Z., Wang, Y., Song, D., 2013. The evaluation of rapid cooling as an anesthetic method for the zebrafish. Zebrafish 1-5. https://doi.org/10.1089/zeb.2012.0858. 00.

Chen, L., Deng, H., Cui, H., Fang, J., Zuo, Z., Deng, J., Li, Y., Wang, X., Zhao, L., 2018. Inflammatory responses and inflammation-associated diseases in organs. Oncotarget 9, 7204-7218. https://doi.org/10.18632/oncotarget. 23208.

Cordero-maldonado, L., Siverio-mota, D., Vicet-muro, L., 2013. Optimization and pharmacological validation of a leukocyte migration assay in zebrafish larvae for the rapid in vivo bioactivity analysis of anti-inflammatory secondary metabolites. PloS One 8 . https://doi.org/10.1371/journal.pone.0075404.

Dorman, H.J.D., Koşar, M., Kahlos, K., Holm, Y., Hiltunen, R., 2003. Antioxidant properties and composition of aqueous extracts from Mentha species, hybrids, varieties, and cultivars. J. Agric. Food Chem. 51, 4563-4569. https://doi.org/10.1021/ jf034108k.

Erukainure, O.L., Ebuehi, O.A.T., Choudhary, I.M., Adhikari, A., Hafizur, R.M., Perveen, S., Muhammad, A., Elemo, G.N., 2014. Iridoid glycoside from the leaves of clerodendrum volubile beauv. Shows potent antioxidant activity against oxidative stress in rat brain and hepatic tissues. J. Diet. Suppl. 11, 19-29. https://doi.org/10.3109/ 19390211.2013.859213.

Europe Council, 2019. European Pharmacopoeia, tenth ed. Ph. Eur. 2-8-25. 
Fabiola, V.T., Ralf, K., Gabriel, B., Ermilo, A.V., Torre, V., Ralf, K., Gabriel, B., Ermilo, A.V., Martha, M., Mirbella, C., 2016. Anti-inflammatory and immunomodulatory effects of Critonia aromatisans leaves: downregulation of pro-inflammatory cytokines. J. Ethnopharmacol. https://doi.org/10.1016/j.jep.2016.06.006.

Fatiha, B., Khodir, M., Farid, D., Tiziri, R., Karima, B., Sonia, O., Mohamed, C., 2012. Optimisation of solvent extraction of antioxidants (phenolic compounds) from Algerian mint (mentha spicata L.). Pharmacogn. Commun. 2. https://doi.org/10. 5530/pc.2012.4.10.

Hyun, E., Bolla, M., Steinhoff, M., Wallace, J.L., Soldato, P., Vergnolle, N., 2004. Antiinflammatory effects of nitric oxide-releasing hydrocortisone NCX 1022 , in a murine model of contact dermatitis. Br. J. Pharmacol. 618-625. https://doi.org/10.1038/sj. bjp.0705854.

Imhof, B.A., Dunon, D., 1995. Leukocyte migration and adhesion. Adv. Immunol. 58, 345-416. https://doi.org/10.1016/S0065-2776(08)60623-9.

Iyer, S.S., Cheng, G., 2012. Role of interleukin 10 transcriptional regulation in inflammation and autoimmune disease. Crit. Rev. Immunol. 32, 23-63.

Jung, Y., Hwan, D., Yeon, J., Young, N., Lee, Y., Bae, S., Yeon, B., Soon, M., Jeong, H., Tae, J., 2014. Anti-inflammatory effect of tricin 4'-O- (threo-guaiacylglyceryl) ether, a novel flavonolignan compound isolated from Njavara on in RAW264 . 7 cells and in ear mice edema. Toxicol. Appl. Pharmacol. 277, 67-76. https://doi.org/10.1016/j. taap.2014.03.001.

Kanchanapoom, T., Kasai, R., Chumsri, P., Hiraga, Y., Yamasaki, K., 2001. Megastigmane and iridoid glucosides from Clerodendrum inerme. Phytochemistry 58, 333-336. https://doi.org/10.1016/S0031-9422(01)00208-4.

Kanchanapoom, T., Chumsri, P., Kasai, R., Otsuka, H., Yamasaki, K., 2005. A new iridoid diglycoside from Clerodendrum chinense. J. Asian Nat. Prod. Res. 7, 269-272. https://doi.org/10.1080/10286020410001690145.

Kar, P., Goyal, A.K., Das, A.P., Sen, A., 2014. Antioxidant and pharmaceutical potential of Clerodendrum L .: an overview. Int. J. Green Pharm. 210-216.

Karin, M., Ben-neriah, Y., 2000. Phosphorylation meets ubiquitination: the Control of NFkB Activity. Annu. Rev. Immunol. 621-663.

Kenyon, N.J., Vliet, A. vander, Schock, B.C., Okamoto, T., Grew, G.M.M.C., Last, J.A., Critical, P., Medicine, C., Nicholas, J., Vliet, A. Van Der, Bettina, C., Okamoto, T. Mcgrew, G.M., 2002. Susceptibility to ozone-induced acute lung injury in iNOS-deficient mice. Am. J. Physiol. Lung Cell Mol. Physiol. 540-545.

Khanapure, S.P., Garvey, D.S., Janero, D.R., Letts, L.G., 2007. Eicosanoids in Inflammatio : biosynthesis, pharmacology, and thera- peutic frontiers. Curr. Top. Med. Chem. 311-340.

Kubes, P., Suzuki, M., Granger, D.N., 1991. Nitric oxide : an endogenous modulator of leukocyte adhesion. Proc. Natl. Acad. Sci. U.S.A. 88, 4651-4655.

Kumar, S., Pandey, A.K., 2013. Chemistry and biological activities of Flavonoids : an overview chemistry and biological activities of Flavonoids : an overview. Sci. World J. https://doi.org/10.1155/2013/162750.

Kumar, V., Bhat, Z.A., Kumar, D., Bohra, P., Sheela, S., 2011. In-vitro anti-inflammatory activity of leaf extracts of Basella Alba Linn. Var. Alba. Int. J. Drug Dev. Res. 3, 176-179.

Lackmann, C., Martinez, M., Rainieri, S., Barranco, A., Hollert, H., Spirhanzlova, P., Velki, M., Seiler, T., 2018. Chemosphere Novel procedures for whole organism detection and quantifi cation of fluorescence as a measurement for oxidative stress in zebra fish (Danio rerio) larvae. Chemosphere 197, 200-209. https://doi.org/10.1016/j. chemosphere.2018.01.045.

Lee, J.Y., Park, W., 2016. Anti-inflammatory effects of oroxylin A on RAW 264.7 mouse macrophages induced with polyinosinic-polycytidylic acid. Exp. Ther. Med. 12, 151-156. https://doi.org/10.3892/etm.2016.3320.

Lee, S., Ko, C., Jee, Y., Jeong, Y., Kim, M., Kim, J., Jeon, Y., 2013. Anti-inflammatory effect of fucoidan extracted from Ecklonia cava in zebrafish model. Carbohydr. Polym. 92, 84-89. https://doi.org/10.1016/j.carbpol.2012.09.066.

Li, H. Bin, Wong, C.C., Cheng, K.W., Chen, F., 2008. Antioxidant properties in vitro and total phenolic contents in methanol extracts from medicinal plants. LWT - Food Sci.
Technol. (Lebensmittel-Wissenschaft -Technol.) 41, 385-390. https://doi.org/10. 1016/j.lwt.2007.03.011.

Liu, S.F., Malik, A.B., 2006. NF- kB activation as a pathological mechanism of septic shock and inflammation. Am. J. Physiol. Lung Cell Mol. Physiol. 622-645. https://doi.org/ 10.1152/ajplung.00477.2005.

Liu, H., Wang, L., Wang, M., 2011. Antioxidant and nitric oxide release inhibition activities of methanolic extract from clerodendrum cyrtophyllum Turcz. Hortic. Environ. Biotechnol. 52, 309-314. https://doi.org/10.1007/s13580-011-0204-7.

Mayadas, T.N., Culllere, X., Lowell, C.A., 2014. The multifaceted functions of neutrophils. Annu. Rev. Pathol. 9, 181-218. https://doi.org/10.1146/annurev-pathol-020712164023. The.

Odobasic, D., Kitching, A.R., Holdsworth, S.R., 2016. Neutrophil-Mediated regulation of innate and adaptive immunity: the role of myeloperoxidase. J. Immunol. Res. https:// doi.org/10.1155/2016/2349817. 2016.

Otava, M., Shkedy, Z., Talloen, W., Verheyen, G.R., Kasim, A., 2015. Identification of in vitro and in vivo disconnects using transcriptomic data. BMC Genom. 16, 1-10. https://doi.org/10.1186/s12864-015-1726-7.

Parvin, M.S., Das, N., Jahan, N., Akhter, M.A., Nahar, L., Islam, E., 2015. Evaluation of in vitro anti - inflammatory and antibacterial potential of Crescentia cujete leaves and stem bark. BMC Res. Notes 1-7. https://doi.org/10.1186/s13104-015-1384-5.

Pompermaier, L., Marzocco, S., Adesso, S., Monizi, M., Schwaiger, S., Neinhuis, C., Stuppner, H., Lautenschläger, T., 2018. Medicinal plants of northern Angola and their anti-inflammatory properties. J. Ethnopharmacol. 216, 26-36. https://doi.org/10. 1016/j.jep.2018.01.019.

Ranasinghe, Priyanga, Ranasinghe, Pathmasiri, Abeysekera, W.P.K.M., Gunatilake, S.B., 2012. In vitro erythrocyte membrane stabilization properties of Carica papaya L. leaf extracts. Pharmacogn. Res. 4. https://doi.org/10.4103/0974-8490.102261.

Saeidnia, S., Manay, A., Abdollahi, M., 2015. From in vitro experiments to in vivo and clinical Studies; pros and. Curr. Drug Discov. Technol. 12, 218-224.

Santangelo, C., Varì, R., Scazzocchio, B., Benedetto, R. Di, Filesi, C., Masella, R., 2007. Polyphenols, intracellular signalling and inflammation. Ann. Ist. Super Sanita 43, 394-405.

Seema Chaitanya Chippada, S.S.V., Bammidi, S.R., Vangalapati, M., 2011. In vitro Anti inflammatory activity of methanol extract of Centella asiatica by HRBC membrane stabilization. RJC 4, 457-460.

Shao, J., Li, Y., Wang, Z., Xiao, M., Liu, J., 2013. 7b , a novel naphthalimide derivative, exhibited anti-inflammatory effects via targeted-inhibiting TAK1 following downregulation of ERK1 /2- and p38 MAPK-mediated activation of NF- $\kappa$ B in LPS- stimulated RAW 264.7 macrophages. Int. Immunopharm. 17, 216-228. https://doi.org/ 10.1016/j.intimp.2013.06.008.

Shrivastava, N., Patel, T., 2007. Clerodendrum and Healthcare : an overview - Part II phytochemistry and biotechnology. Med. Aromat. Plant Sci. Biotechnol. 1, 209-223.

Sudsai, T., Wattanapiromsakul, C., 2013. Inhibition of nitric oxide production by compounds from Boesenbergia longiflora using lipopolysaccharide-stimulated. Songklanakarin J. Sci. Technol. 35, 317-323.

Wang, P., Sun, L., Tan, J., Xu, J., Guo, F., Li, Y., 2012. Fitoterapia Two new glycosidated coumaramides from Clerodendron cyrtophyllum. Fitoterapia 83, 1494-1499. https:// doi.org/10.1016/j.fitote.2012.08.016.

Yang, L.L., Wang, G.Q., Yang, L.M., Huang, Z.B., Zhang, W.Q., Yu, L.Z., 2014. Endotoxin molecule lipopolysaccharide-induced zebrafish inflammation model: a novel screening method for anti-inflammatory drugs. Molecules 19, 2390-2409. https:// doi.org/10.3390/molecules19022390.

Zhang, Jun-Ming, An, Jianxiong, 2007. Cytokines, inflammation and pain. Int. Anesthesiol. Clin. 45, 27-37. https://doi.org/10.1097/AIA.0b013e318034194e. Cytokines.

Zhou, J., Zheng, X., Yang, Q., Liang, Z., Li, D., Yang, X., Xu, J., 2013. Optimization of ultrasonic-assisted extraction and radical-scavenging capacity of phenols and flavonoids from clerodendrum cyrtophyllum Turcz leaves. PloS One 8, 1-8. https://doi. org/10.1371/journal.pone.0068392. 